\title{
SELEÇÃO DE DESCRITORES NA CARACTERIZAÇÃO DE GERMOPLASMA DE PASPALUM ATRAVÉS DE COMPONENTES PRINCIPAIS
}

\author{
ELIZABETH STRAPASSON \\ Licenciada em Ciências - Habilitação Matemática
}

Orientador : Prof. Dr. ROLAND VENCOVSKY

Dissertação apresentada à Escola Superior de Agricultura "Luiz de Queiroz", Universidade de São Paulo, para obtenção do título de Mestre em Agronomia, Área de Concentração: Estatística e Experimentação Agronômica.

P I R AC I C A B A

Estado de São Paulo - Brasil

Abril - 1997 


\section{Dados Internacionais de Catalogação na Publicação (CIP) DIVISÃo DE BIBLIOTECA E DOCUMENTAÇÃO - Campus "Luiz de Queiroz"/USP}

Strapasson, Elizabeth

Seleção de descritores na caracterizaçăo de germoplasma de paspalum através de componentes principais / Piracicaba, 1997.

95 p. : il. 1997.

Dissertação (mestrado) - Escola Superior de Agricultura Luiz de Queiroz, Bibliografia.

1. Análise de componente principal 2. Capim ramirez 3. Descritor botânicoagronómico 4. Estatistica aplicada 5. Germoplasma 6. Graminea forrageira 7. Seleção I. Título. 


\title{
SELEÇÃO DE DESCRITORES NA CARACTERIZAÇÃO DE GERMOPLASMA DE PASPALUM ATRAVÉS DE COMPONENTES PRINCIPAIS
}

\author{
ELIZABETH STRAPASSON
}

Aprovado em : 02.06.1997

Comissão julgadora:

Prof. Dr. Roland Vencovsky ESALQ/USP

Prof. Dr. Carlos Tadeu dos Santos Dias ESALQ/USP

Pesq. Dr. Luiz Alberto Rocha Batista CPPSE/EMBRAPA

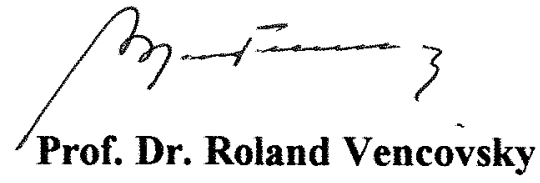

Orientador 
Quando o homem fala - Deus se cala.

Quando o homem pensa - Deus se dispensa.

Quando o homem deseja algo - Deus se eclipsa.

Huberto Rohden 
Aos meus pais,

Maria Pontes Strapasson e Pedro Strapasson

Dedico.

Às minhas irmãs e sobrinha,

Fátima, Marilde e Fabiana

Ofereço. 


\section{AGRADECIMENTOS}

Ao Professor Dr. Roland Vencovsky pela orientação, apoio e incentivo.

Ao Departamento de Matemática e Estatística da ESALQ/USP pela aceitação, e seus docentes pelos ensinamentos e convívio.

A todos os funcionários do Departamento de Matemática e Estatística da ESALQ/USP, Expedita, Luciane, Rosa, Rosni e Solange.

A todos os colegas da pós-graduação, em especial aos amigos Cláudio, Renata, Sílvia e Silvano pelo companheirismo e amizade.

A Professora Doris Gomez Ticerán, pela amizade, apoio e contribuição na realização deste trabalho.

A Harumi Otaguro e Gislaine pela amizade e incentivo.

Ao Conselho Nacional de Desenvolvimento Científico e Tecnológico $\mathrm{CNPq}$, pela concessão da bolsa de estudos.

Ao Centro de Pesquisa de Pecuária do Sudeste - CPPSE/EMBRAPA, pela cessão dos dados utilizados neste trabalho.

Ao Eng ${ }^{0}$ Agrônomo Dr. Luiz Alberto Rocha Batista, pesquisador do CPPSE/EMBRAPA, pela confiança e auxílio na obtenção dos dados.

A bibliotecária Eliana Sabino, pela revisão da referência bibliográfica. 


\section{SUMÁRIO}

Página

RESUMO $\ldots \ldots \ldots \ldots \ldots \ldots \ldots \ldots \ldots \ldots \ldots \ldots \ldots \ldots$ viii

SUMMARY $\ldots \ldots \ldots \ldots \ldots \ldots \ldots \ldots \ldots \ldots \ldots \ldots \ldots$



2. REVISÃO DE LITERATURA $\ldots \ldots \ldots \ldots \ldots \ldots \ldots \ldots \ldots \ldots$



2.1.1. Paspalum guenoarum ..................... 03

2.1.2. Paspalum plicatulum . . . . . . . . . . . . . . . . 05

2.2. A Utilização da Análise Multivariada . . . . . . . . . . . . . . . 06

2.3. Análise de Componentes Principais . . . . . . . . . . . . . . 07

2.4. Seleção de Descritores Botânico-Agronômicos . . . . . . . . . . . . . 13

3. MATERIAL E MÉTODOS $\ldots \ldots \ldots \ldots \ldots \ldots \ldots \ldots \ldots \ldots$

3.1. Localização do Germoplasma, Clima e Solo . . . . . . . . . . . . . . 18

3.2. Material e Delineamento Experimental . . . . . . . . . . . . . . 20

3.3. Descritores Botânico-Agronômicos Avaliados . . . . . . . . . . . . 21

3.4. Metodologias Estatísticas . . . . . . . . . . . . . . . . . 30

3.4.1. Análise de Componentes Principais . . . . . . . . . . . . $\quad 30$

3.4.1.1. Obtenção dos Componentes Principais . . . . . . . . . . 32

3.4.1.2. Importância Relativa de um Componente Principal . . . . 36

3.4.2. Seleção dos Descritores Botânico-Agronômicos . . . . . . . . . . 37 
3.4.3. Comparação dos Componentes Principais . . . . . . . . . . 38

3.4.4. Análise de Variância Univariada . . . . . . . . . . ...... 40

3.4.5. Programas Computacionais Utilizados . . . . . . . . . . . . $\quad 40$

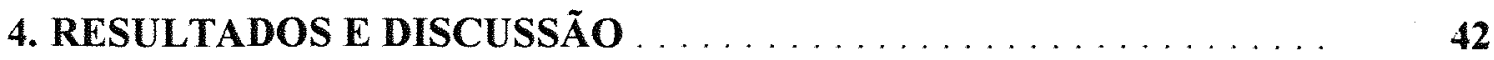

4.1. Seleção de Descritores Botânico-Agronômicos . . . . . . . . . . . . . 42

4.1.1. Seleção de Descritores Reprodutivos . . . . . . . . . . . . . $\quad 42$

4.1.1.1. Comparação dos Componentes Principais de Descritores Reprodutivos ....................... 47

4.1.2. Seleção de Descritores Vegetativos . . . . . . . . . . . . . . 49

4.1.2.1. Comparação dos Componentes Principais de Descritores Vegetativos . . . . . . . . . . . . . . 56

4.1.3. Análise de Variância Univariada dos Descritores Agronômicos . . 57

4.1.4. Seleção de Descritores Agronômicos . . . . . . . . . . . . . 60

4.1.4.1. Comparação dos Componentes Principais de Descritores Agronômicos . . . . . . . . . . . . . . . . . . . 63

4.1.5. Seleção de Descritores Reprodutivos, Vegetativos, Agronômicos Analisados Conjuntamente . . . . . . . . . . . . . . . . 64

4.1.5.1. Comparação dos Componentes Principais de Descritores Reprodutivos, Vegetativos e Agronômicos Analisados Conjuntamente ................... 70

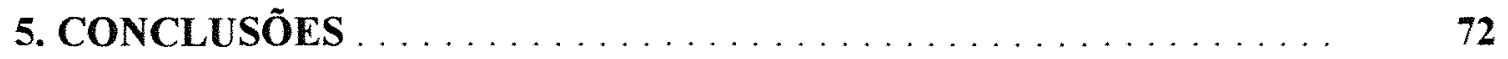



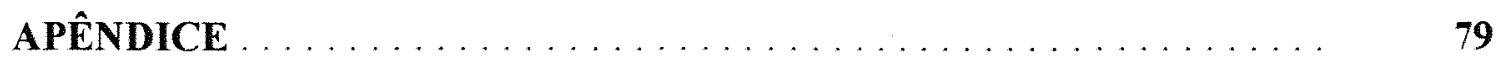




\title{
SELEÇÃO DE DESCRITORES NA CARACTERIZAÇÃO DE GERMOPLASMA DE PASPALUM ATRAVÉS DE COMPONENTES PRINCIPAIS
}

\author{
Autora: ELIZABETH STRAPASSON \\ Orientador: PROF. DR. ROLAND VENCOVSKY
}

\section{RESUMO}

Este estudo teve como objetivo selecionar os descritores botânicoagronômicos que melhor se prestam para caracterizar acessos das espécies Paspalum guenoarum e Paspalum plicatulum, através de componentes principais.

Foram avaliados 15 descritores reprodutivos, 22 vegetativos e 21 agronômicos, sendo que os agronômicos compreenderam 7 descritores para a avaliação anual, 7 descritores para a avaliação de inverno (época das secas) e 7 descritores para a avaliação de verão (época das chuvas). Utilizou-se a análise de componentes principais para descartar os descritores considerados redundantes ou não discriminantes. Após a seleção de descritores reprodutivos, vegetativos e agronômicos separadamente, foi realizada uma análise de componentes principais considerando estes caracteres conjuntamente, a fim de se proceder a uma nova seleção.

Através do teste $\mathrm{F}$, realizado em análises de variância univariada, ficou evidenciada a diversidade genética entre os acessos, para todos os descritores agronômicos.

O método utilizado permitiu uma redução de $53 \%, 68 \%$ e $43 \%$ dos descritores reprodutivos, vegetativos e agronômicos, respectivamente, do conjunto inicialmente considerado. Como descritores mais importantes destacaram-se: PR, CE, 
EFL (reprodutivos), DIPB, CMB, LMBBASE (vegetativos) e PORMSANO, DIVERAO (agronômicos), o que representa um descarte de $86 \%$ do total de descritores utilizados na caracterização dos acessos. Verificou-se também que os descritores agronômicos por serem mais influenciados por fatores ambientais tiveram uma menor participação nesta caracterização, uma vez que dos oito descritores selecionados, seis foram reprodutivos e vegetativos.

Para os descritores vegetativos o método de descarte não foi tão satisfatório quanto para os demais, devendo-se ressaltar que suas estimativas podem não ter refletido com boa exatidão as associações existentes entre os mesmos tendo em vista o pequeno número de acessos (26) e a quantidade elevada de descritores (22) considerados.

O método de componentes principais mostrou-se útel para selecionar os descritores mais importantes na descrição da variabilidade presente na coleção de acessos do germoplasma estudado. 


\title{
SELECTION OF DESCRIPTORS FOR PASPALUM GERMPLASM CHARACTERIZATION THROUGH PRINCIPAL COMPONENTES
}

\author{
Author: ELIZABETH STRAPASSON \\ Adviser: PROF. Dr. ROLAND VENCOVSKY
}

\section{SUMMARY}

The objective of this study was to select the most appropriate descriptors for characterization of Paspalum guenoarum and Paspalum plicatulum, through principal components.

Fifteen reproductive, 22 vegetative and 21 agronomic descriptors were evaluated; the agronomic ones comprised seven descriptors for annual, winter, and summer evaluations, respectively. Principal components were used to discard redundant or non-discriminative descriptors. After selection of the reprodutive, vegetative, and agronomic descriptors, the principal components analysis was performed using all selected descriptors together to make a new selection.

Significant differences for agronomic descriptors were detected by univariate analysis of variance ( $\mathrm{F}$ test), suggesting that there are genetic differences among the accessions.

The principal component analysis allowed a reduction of $53 \%, 68 \%$, and $43 \%$, respectively, in the number of initial descriptors considered. The following descriptors were identifyed as important for characterization: $P R, C E, E F L$ (reproductive), DIPB, CMB, LMBBASE (vegetative) and PORMSANO, DIVERAO (agronomic), representing a rejection of $86 \%$ of the total descriptors used in the 
caracterization of the accessions. It was also verified that the agronomic descriptors, being more easily influenced by environmental factors, played a minor role in this characterization, since out of the eight descriptors selected, six were reproductive and vegetative.

The method for discarding variables was less effective for vegetative than for other types of descriptors. However, it must be emphasized that these estimates may not necessarily express the real associations between descriptors, due to the small number of accessions (26) and high quantity of descriptors (22) used.

The principal components method was considered a powerfull tool for selecting the most important descriptors to identify the genetic variability in this germplasm collection. 


\section{INTRODUÇÃO}

O gênero Paspalum ocupa um lugar destacado entre as gramíneas brasileiras. Não só é aquele que engloba o maior número de espécies nativas, mas é também, o que reúne o maior número de espécies com bom valor forrageiro. A disponibilidade de acessos de germoplasma dessas espécies vem crescendo nos últimos anos, de forma consistente, por meio de coletas no Brasil. O interesse pelo germoplasma de Paspalum no Brasil não é recente, pois na década de 30 já se mantinham coleções vivas no Rio Grande do Sul e Rio de Janeiro (Valls, 1987).

Gramíneas forrageiras nativas são uma opção e, aquelas pertencentes ao gênero Paspalum, assumem grande importância tanto nas regiões tropicais, quanto subtropicais no Brasil, onde se encontram sistemas extensivos de criação de rebanhos bovinos e onde o regime de alimentação é constituído em quase sua totalidade por pastagens naturais, com produtividade variável. A seleção e o melhoramento genético animal no Brasil, estão muito à frente das pesquisas sobre alimentação dos rebanhos nacionais e, se a intenção é aumentar os patamares de produtividade da pecuária brasileira, a primeira área com a qual se deve ter preocupação hoje, é com a melhoria da alimentação desse rebanho (Casa, 1995).

A identificação de plantas forrageiras bem adaptadas às condições ecológicas de uma determinada região e que apresentem alta produtividade, persistência $\mathrm{e}$ valor nutritivo compativel com as exigências dos animais, representa a primeira etapa de um programa de melhoramento de pastagens, visando à implantação de uma pecuária de índices zootécnicos satisfatórios (Costa et al., 1989).

Procurando atender à demanda em proteina animal da Região Sudeste, o Centro de Pesquisa Agropecuária do Sudeste, unidade da Empresa Brasileira de 
Pesquisa Agropecuária (CPPSE/EMBRAPA), está desenvolvendo pesquisas relacionadas ao gênero Paspalum, as quais visam aumentar a eficiência dos atuais sistemas de produção de bovinos (carne e leite) através do uso de plantas forrageiras mais produtivas, pertencentes ao gênero Paspalum, principalmente do grupo Plicatula, com maior qualidade nutricional e menor redução da produtividade no periodo seco.

Nestas pesquisas, será utilizada a variabilidade genética disponivel nas espécies do gênero Paspalum, devido ao seu elevado potencial forrageiro, para a obtenção de novos cultivares com especificidade aos ecossistemas dessa região. Quanto maior for a variabilidade genética apresentada pelo material maiores serão as possibilidades de sucesso.

Acessos em bancos de germoplasma são usualmente caracterizados por descritores botânico-agronômicos, devendo-se selecionar dentre esses descritores aqueles mais importantes na descrição da variabilidade presente no germoplasma.

Assim, o objetivo desse trabalho foi selecionar os descritores botânicoagronômicos que melhor se prestam para caracterizar acessos de P.guenoarum $e$ P.plicatulum, do grupo Plicatula, com a utilização de técnicas multivariadas. 


\section{REVISÃO DE LITERATURA}

\subsection{Forrageira}

\subsubsection{Paspalum guenoarum}

Segundo Alcântara \& Bufarah (1992), o Paspalum guenoarum Arech., tem como nome comum capim ramirez e é originário do Paraguai, Argentina e possivelmente África. As principais características morfológicas e agronômicas são: gramínea perene, dotada de rizomas, alcançando de $80 \mathrm{~cm}$ a $100 \mathrm{~cm}$ de altura, com folhas verde escuras e com nervuras bem visiveis, a inflorescência é uma panícula que pode atingir $150 \mathrm{~cm}$ de altura, é uma espécie de solos médios, vegeta bem onde a temperatura varia de $0^{\circ} \mathrm{C}$ a $40^{\circ} \mathrm{C}$, sendo bastante resistente ao frio e à geada, além de suportar bem a seca. Floresce no periodo das águas (verão) e inicia a estação seca como uma forragem de boa qualidade, tornando-se boa forrageira para o inverno, sua propagação se dá através de sementes que possuem alto valor germinativo, chegando a produzir cerca de $500 \mathrm{Kg} / \mathrm{ha}$ de sementes e é muito palatável aos animais. As Figuras 1 e 2 mostram exemplares de acessos da espécie P.guenoarum. 




Paspalum guenoarum Arech

Figura 1 - Paspalum guenoarum Arech. - acesso de código BRA-003824 CPPSE/EMBRAPA - São Carlos.



Figura 2 - Paspalum guenoarum Arech. - acesso de código BRA-014851 CPPSE/EMBRAPA - São Carlos. 


\subsubsection{Paspalum plicatulum}

De acordo com Alcântara \& Bufarah (1992), seu nome científico é Paspalum plicatulum Michx., e o nome comum plicatulum, pasto negro, tendo como origem a Guatemala e a Colômbia. Suas principais características morfológicas e agronômicas são: gramínea de touceiras com altura até $100 \mathrm{~cm}$, folhas pilosas de $40 \mathrm{~cm}$ de comprimento, inflorescências com 10 a 13 rácemos de $2 \mathrm{~cm}$ a $6 \mathrm{~cm}$ de comprimento, situados num mesmo eixo, gramínea tropical com crescimento em épocas quentes e úmidas, adaptadas a regiões com precipitação de $750 \mathrm{~mm}$ ou mais, vegeta bem em locais pobres e com ocorrência de secas e é tolerante a encharcamento ou alagamento por curto período. Possui crescimento de primavera-verão, e seu florescimento é encontrado em períodos curtos no final do verão. A propagação é por sementes provenientes de autopolonização em sua maioria, com produção de $600 \mathrm{Kg} / \mathrm{ha}$ a $800 \mathrm{~kg} / \mathrm{ha}$ de sementes, e requer dias curtos para florir, adaptando-se bem nos trópicos. As Figuras 3 e 4 mostram exemplares de acessos da espécie P.plicatulum.

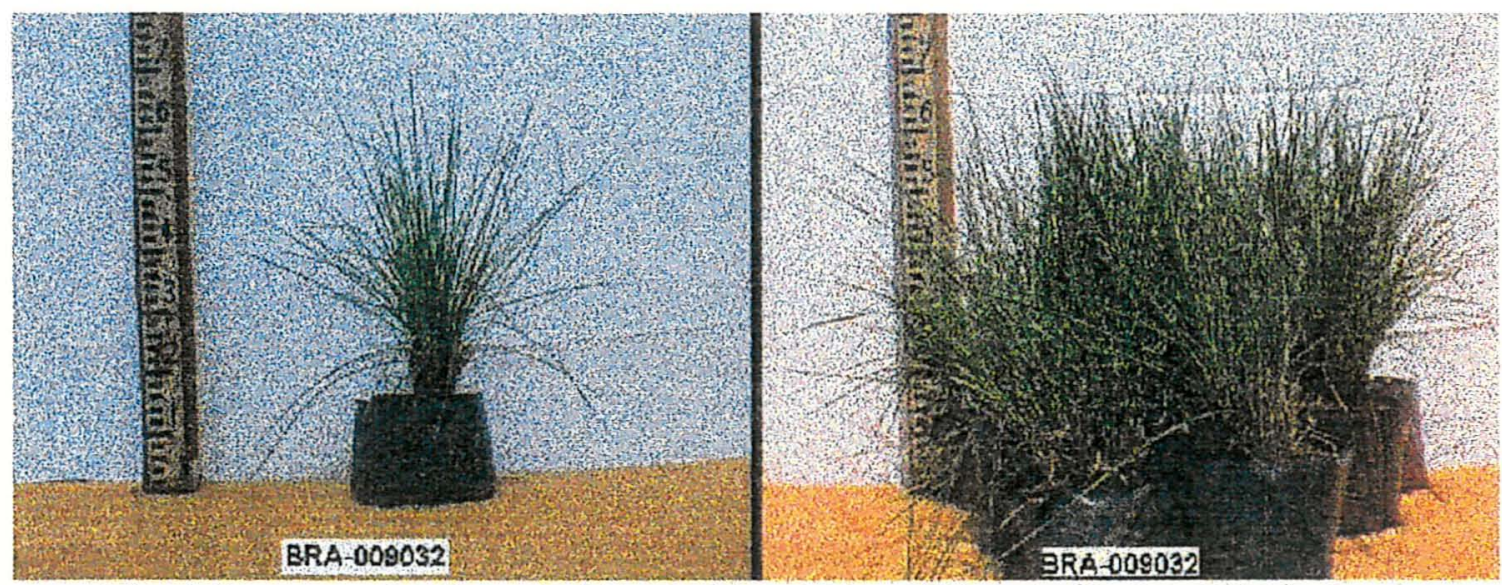

Paspalum plicatulum Michx.

Figura 3 - Paspalum plicatulum Michx. - acesso de código BRA-009032 CPPSE/EMBRAPA - São Carlos. 


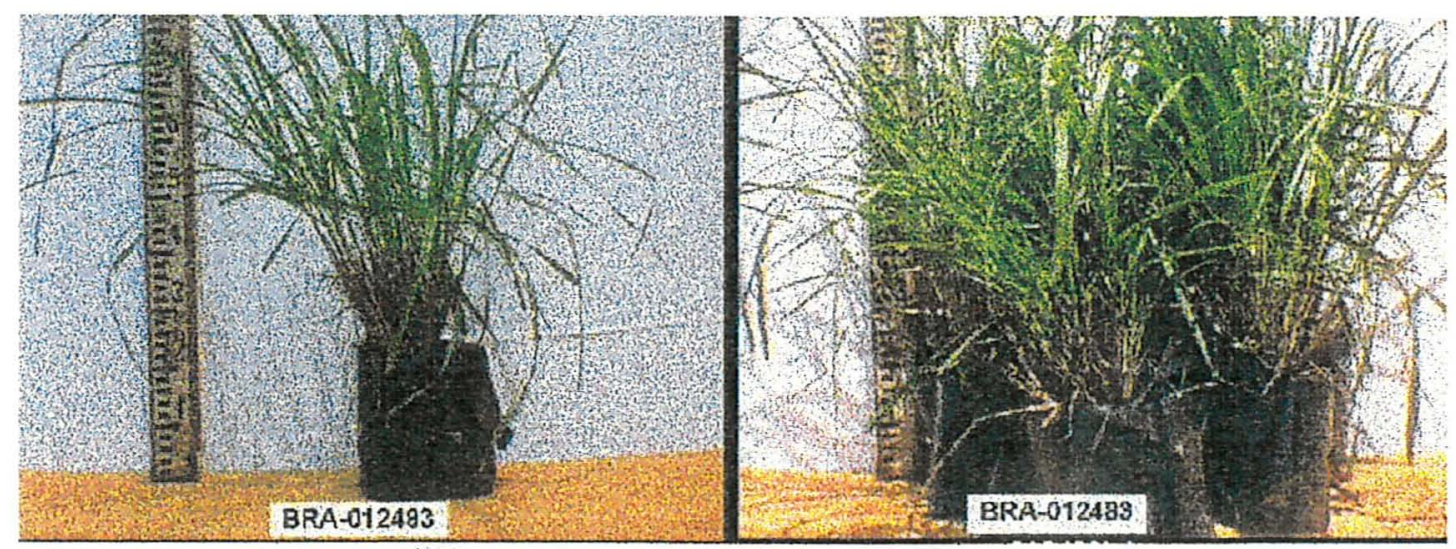

Paspalum plicatulum Michx.

Figura 4 - Paspalum plicatulum Michx. - acesso de código BRA-012483 CPPSE/EMBRAPA - São Carlos.

\subsection{A Utilização da Análise Multivariada}

Segundo Jeffers (1967), existe uma necessidade em aplicar os métodos disponíveis na análise multivariada, incluindo a análise de componentes principais, a fim de testar o valor prático dessas técnicas, uma vez que nos artigos publicados em diversas revistas científicas, os autores declaravam que esta técnica não era bem sucedida em nenhuma interpretação prática. Embora a análise de componentes principais e outras técnicas multivariadas se apresentassem descritas em muitos textos, a ênfase era voltada para a teoria fundamental dos métodos, havendo um número limitado de publicações a respeito de exemplos práticos, que incluíssem detalhes suficientes para possibilitar ao leitor uma interpretação clara e útil dos resultados da análise. Em parte, esta carência de exemplos práticos era por causa de dificuldades em computação, mas atualmente com o avanço da informática, a aplicação destas técnicas vem acontecendo em diversas áreas de pesquisas, mais acentuadamente.

As técnicas estatísticas multivariadas apresentam a vantagem de que, para agrupar e/ou descrever um conjunto de indivíduos, consideram simultaneamente 
vários caracteres (variáveis ou descritores) isto é, levam em conta a correlação existente entre todos os caracteres em estudo (Martinez Wilches, 1983). Estas técnicas, segundo Cruz (1990), têm sido apresentadas como procedimentos eficientes no melhoramento de plantas em razão de combinarem as múltiplas informações provenientes de uma unidade experimental, de modo que é possivel selecionar ou predizer fenômenos genéticos baseando-se simultaneamente em um complexo de variáveis de importância genética e/ou evolutiva.

Van Laar (1987), salienta que a análise multivariada é largamente usada em pesquisas com plantas e animais selvagens, porém merece mais atenção em silvicultura e experimentos a ela relacionados. $\mathrm{O}$ autor faz uma revisão de alguns métodos multivariados e cita seu campo de aplicação.

Dentre as técnicas multivariadas utilizadas no melhoramento de plantas destacam-se, a análise de componentes principais, a análise de variáveis canônicas, a análise de agrupamento ("Cluster Analysis") e as medidas de dissimilaridade como as distâncias Euclideana e de Mahalanobis.

\subsection{Análise de Componentes Principais}

Conforme citado por Morrison (1976), o primeiro trabalho sobre componentes principais foi descrito por Pearson ${ }^{1}$ em 1901. Posteriormente, Hotelling ${ }^{2}$ apresentou novos trabalhos com a aplicação desta técnica, a qual é utilizada em diversas áreas das ciências.

${ }^{1}$ PEARSON. K. On lines and planes of closest fit to systems of points in space. Philosophycal Magazine, v. 2, p. 559-572, 1901.

${ }^{2}$ HOTELLING, H. Analysis of a complex of statistical variables in to principal components. Journal of Education Psychology, v. 24, p. 417-441, 1933.

${ }^{2}$ HOTELLING, H. Simplified calculation of principal components. Psychometrika, v. 1, p. 27-35, 1936. 
Esta técnica consiste em transformar um conjunto de $p$ variáveis originais, sendo que não existe um relacionamento funcional entre elas, (por exemplo, altura da planta, produção, época de florescimento, etc) $X_{1}, X_{2}, \ldots, X_{p}$, pertencentes a $n$ indivíduos ou populações (por exemplo, clones, linhagens, etc) em um novo conjunto de variáveis $Y_{1}, Y_{2}, \ldots, Y_{p}$, de dimensão equivalente, mas com propriedades importantes que são de grande interesse em certos estudos de melhoramento (Cruz \& Regazzi, 1994). Cada componente principal é uma combinação linear das variáveis originais. Além disso, eles são não correlacionados entre si e construídos de maneira a explicar o máximo da variação total dessas variáveis originais.

A metodologia da análise de componentes principais trata-se de uma técnica puramente matemática, e está descrita principalmente nos livros de Morrison (1976), Mardia et al. (1979) e Johnson \& Wichern (1982).

Morrison (1976) define o primeiro componente principal $\left(Y_{1}\right)$ de um conjunto de $\mathrm{p}$ variáveis, $\mathrm{X}_{1}, \mathrm{X}_{2}, \ldots, \mathrm{X}_{\mathrm{p}}$, contidas no vetor $\mathrm{X}^{\prime}=\left(\mathrm{X}_{1}, \mathrm{X}_{2}, \ldots, \mathrm{X}_{\mathrm{p}}\right)$ como sendo a combinação linear,

$$
Y_{1}=b_{11} X_{1}+b_{21} X_{2}+\ldots+b_{p 1} X_{p}=b^{\prime}{ }_{1} X
$$

cujos coeficientes $\mathbf{b}_{\mathbf{i} 1}$ são elementos do vetor característico $\mathbf{b}_{1}$, associado à maior raiz característica $\left(\lambda_{1}\right)$ da matriz de covariância amostral, $\mathbf{S}$, das variáveis $X_{i ' s .} O$ segundo componente principal $\left(\mathrm{Y}_{2}\right)$ estará associado à segunda maior raiz característica $\left(\lambda_{2}\right)$, e assim sucessivamente, até que toda a variância tenha sido explicada. Os autovalores (ou raízes características) ordenados, ou seja, $\lambda_{1} \geq \lambda_{2} \geq \Lambda \geq \lambda_{\mathrm{p}} \geq 0$ são as variâncias amostrais dos componentes principais. O primeiro componente também é definido como aquele de maior importância, uma vez que retém a maior parte da variação total encontrada nos dados originais.

Por construção, os vetores característicos são ortogonais, implicando que a soma das variâncias dos componentes corresponda ao somatório das variâncias das variáveis, denominada variância total e que a covariância entre os componentes seja nula. 
O sinal e a magnitude dos coeficientes de cada variável original que compõem um componente principal, indicam a direção e a importância da variável na definição do componente.

A técnica envolve a matriz de covariância amostral $\mathbf{S}$ ou a matriz de correlação $\mathbf{R}$, sendo que a maioria das aplicações tem envolvido esta última (Morrison, 1976). Isso porque, freqüentemente, as variáveis têm escalas diferentes (por exemplo, idade em anos, peso em quilos, altura em metros, etc) devendo ser padronizadas. Após essa transformação todas as variáveis originais têm a mesma variância unitária e, dessa maneira, a base para extração dos componentes principais é a matriz de correlação $\mathbf{R}$. Este autor ainda salienta que os componentes obtidos a partir de $\mathbf{S}$ e $\mathbf{R}$, não são os mesmos.

Em geral, os pesquisadores têm optado pela representação gráfica quando os dois primeiros componentes envolvem cerca de $70 \%$ a $80 \%$ da variação total. Nos casos em que este limite não é atingido, a análise é complementada pela dispersão gráfica em relação ao terceiro e quarto componentes (Cruz, 1990).

$\mathrm{O}$ uso da análise de componentes principais na pesquisa agrícola, segundo Jeffers (1972), pode ser resumida para os seguintes propósitos: a) examinar as correlações entre caracteres estudados; b) resumir um grande conjunto de caracteres em outro menor e de sentido biológico; c) avaliar a importância de cada caráter e promover a eliminação daqueles que contribuem pouco para a variação total; d) construir indices que possibilitem o agrupamento de indivíduos; e) agrupamento taxonômico dos indivíduos em classes. Atualmente esta análise tem sido um dos métodos mais amplamente utilizados no melhoramento de plantas, uma vez que, além da distribuição gráfica da divergência entre os genótipos, ela possibilita a identificação dos caracteres menos e mais representativos para explicar a variância total (Pereira, 1989).

Esta metodologia também vem sendo aplicada numa gama de espécies vegetais com os mais diversos propósitos. A identificação de genitores divergentes para hibridação e geração de populações segregantes, a avaliação da divergência genética 
entre acessos em germoplasmas e a avaliação da uniformidade em cultivos são algumas das muitas aplicações da técnica de componentes principais (Dias, 1994).

A seguir serão apresentadas algumas pesquisas que envolvem o uso da técnica de análise de componentes principais.

Jeffers (1967), apresentou dois casos de estudos na aplicação da análise de componentes principais, sendo que o primeiro teve como objetivo determinar se o corte de madeira era suficientemente resistente para seu uso em minas de carvão. A análise de componentes principais foi aplicada a 180 estacas de pinho Corsican de East Anglia, e 13 variáveis foram medidas em cada estaca. Segundo o autor é necessário decidir sobre o número de componentes que tenham alguma significância prática. $\mathrm{O}$ método utilizado é o de considerar só aqueles componentes que têm autovalores maiores ou iguais a um, considerando neste caso como sendo de significância prática os quatro primeiros componentes, explicando cerca de $74 \%$ do total da variabilidade. $O$ autor, no entanto, decidiu por manter os seis primeiros, devido à possibilidade de interpretá-los, obtendo assim cerca de $87 \%$ da variabilidade total.

No segundo caso estava-se interessado no estudo sobre a variação em 40 indivíduos pulgões. Dezenove variáveis foram incluídas neste estudo. Pulgões são dificeis de identificar com alguma certeza por chaves taxonômicas convencionais, assim utilizou-se a análise de componentes principais para fornecer orientação sobre o número de grupos ou taxa distintos na coleção. Os dois primeiros componentes explicaram $85 \%$ do total da variabilidade. A representação gráfica com os eixos formados por esses dois componentes sugeriram a existência de quatro grupos de insetos.

Akoroda (1983), para identificar os caracteres importantes que explicam a maior variação entre inhames amarelos, Dioscorea cayenensis Lam., para o uso em agrupamentos de rotina, estudou 20 acessos usando análise de componentes principais com 49 caracteres. Baseado nesta técnica, seis caracteres foram escolhidos para a construção de gráficos especificos, cujos agrupamentos de acessos tiveram uma alta correspondência com aqueles indicados pela análise de componentes principais nos três primeiros eixos. 
Caradus et al. (1989), avaliando 109 cultivares de uma coleção mundial de trevo branco (Trifolium repens $\mathrm{L}$.), concluíram que os quatro primeiros componentes explicaram $31 \%, 20 \%, 15 \%$ e $10 \%$, respectivamente da variação total. O primeiro componente pareceu estar relacionado com os fatores morfológicos da planta, o segundo com a cianogênese e o período máximo de florescimento, o terceiro com a ausência e a presença de um marcador branco da folha e o quarto como sendo uma medida dos caracteres marcadores das quatro folhas. Uma representação gráfica dos dois primeiros componentes revelou quatro grupos distintos de cultivares.

Jolicoeur \& Mosimann (1960) estudaram 24 machos e 24 fềmeas de tartarugas (Chrysemys picta marginata) na tentativa de avaliar a aplicabilidade da análise de componentes principais para entender a variação do tamanho e forma em grupos de organismos vivos. Cada espécime foi representada no estudo por um conjunto de três variáveis: comprimento, largura e peso da carapaça. A análise de componentes principais descobriu três direções não correlacionadas e mutuamente perpendiculares, sendo que o primeiro componente correspondeu à direção do aumento do tamanho e pode ser interpretado como uma direção do crescimento. O segundo e terceiro componentes corresponderam à variação de diversos caracteres e foram interpretados como direções da variação da forma. Aspectos numéricos e geométricos foram discutidos em detalhes, concluindo-se que a análise de componentes principais da variação de tamanho e forma seria apropriada em estudos de crescimento relativo sempre que se consideram caracteres biométricos múltiplos.

Ahamad (1967), aplicou a análise de componentes principais em um período de 14 anos. As dezoito variáveis consideradas estavam relacionadas com os crimes cometidos neste periodo. Os três primeiros componentes explicaram $92 \%$ da variabilidade total, sendo que para a maioria dos crimes, a variação pôde ser reproduzida considerando somente o primeiro componente. Segundo o autor este componente pareceu estar identificado com a mudança da população, sugerindo que muito do acréscimo na taxa de crime pode ser explicado pelo rápido crescimento na população. Este estudo recebeu alguns comentários críticos de Walker (1967), que questionou os 
valores que conduziram à análise de componentes dos dados e criticou a interpretação da análise de regressão, mas a questão aqui é a análise de componentes principais.

Curi (1993) estudou 125 países avaliados por um conjunto de 26 indicadores sociais, econômicos, demográficos, de saúde, culturais e educacionais usando três métodos estatísticos multivariados: 1- análise de agrupamento, 2- análise de componentes principais e 3- análise de variância multivariada. A análise de componentes principais possibilitou identificar as variáveis mais discriminatórias. $\mathrm{O}$ primeiro componente reteve $68 \%$ da informação contida no conjunto das 26 variáveis originais e pôde ser considerado como um "índice de padrão de vida" do país. O segundo componente reteve apenas $8 \%$ da informação contida nas variáveis originais, e seu significado prático mereceu pouco destaque. Em um sistema de coordenadas, utilizando os pares ordenados do primeiro e segundo componentes $\left(\mathrm{Y}_{1}\right.$ e $\left.\mathrm{Y}_{2}\right)$ de cada país, foi possível verificar a formação de cinco grupos de países, resultado concordante com o dendrograma da análise de agrupamento.

A técnica de componentes principais também é muito utilizada na avaliação da divergência genética entre genótipos ou populações. Dentre os vários trabalhos existentes pode-se citar os apresentados por Hussaini et al. (1977), o qual, utilizando análise de variância em 640 acessos de milheto, Eleusine coracana L., encontrou diferenças significativas entre os 18 caracteres selecionados. Estes dados foram submetidos a uma análise de componentes principais, sendo que 12 grupos foram identificados com base nos dois primeiros componentes principais, que explicaram 55,9\% da variância total.

Martinez Wilches (1983), avaliou a divergência genética entre 34 variedades de amendoim, com base em 13 caracteres, resultando que os quatro primeiros componentes explicaram $74 \%$ da variação total.

Miranda et al. (1988), estimaram a divergência genética entre seis cultivares de pimentão (Capsicum annuum L.), avaliados juntamente com seus híbridos num sistema dialélico. Para a obtenção das estimativas das distâncias euclideanas foram 
utilizados os escores dos dois primeiros componentes principais que envolveram cerca de $89 \%$ da variação total.

Risi \& Galvey (1989), avaliando o padrão da diversidade genética em uma coleção de quinoa ( Chenopodium quinoa Willd), puderam observar que o primeiro componente principal caracterizou aqueles acessos com germinação rápida, responsável por produzir plantas menores com inflorescências pequenas, e o segundo componente com aqueles responsáveis pelo desenvolvimento de inflorescências maiores. Todavia não houve clareza na separação dos componentes importantes e não importantes para a caracterização.

Pulcinelli et al. (1993), investigaram a divergência genética existente entre seis populações de Eucalyptus grandis e duas de Eucalyptus saligna. Os dois primeiros componentes principais explicaram $95,7 \%$ da variação total. O gráfico de dispersão de escores permitiu a identificação de três grupos de populações.

\subsection{Seleção de Descritores Botânico-Agronômicos}

Uma das vantagens da análise de componentes principais é a de identificar os descritores, variáveis ou caracteres mais importantes diante da variação total disponivel entre os individuos avaliados. Desta forma, além de identificar os descritores de maior interesse, existe a possibilidade de eliminar aqueles que contribuem pouco para a explicação da variância total.

Segundo Daher (1993), a avaliação de grande número de descritores tem sido um procedimento generalizado em razão da ausência de informação precisa sobre a real contribuição dos descritores na caracterização da variabilidade. Porém, à medida que cresce o número de descritores, aumenta também a possibilidade de eles serem redundantes ou altamente correlacionados uns com os outros. Consequentemente, ocorre acréscimo no trabalho de avaliação, o que não implica, necessariamente, em acréscimo de precisão na caracterização. 
Sabe-se que todo caráter deve contribuir de alguma maneira para a descrição da variabilidade do germoplasma e, por sua vez, seu emprego único não quantifica toda a variação existente. Portanto, torna-se altamente desejável eliminar os descritores considerados como redundantes, com baixa variabilidade, com baixa estabilidade de expressão ou de dificil mensuração, enquanto isso não provoque uma perda significativa de informação geral (Pereira, 1989).

Hussaini et al. (1977), estudando o comportamento de 29 descritores botânico-agronômicos de milheto, concluíram que a maior parte dos caracteres vegetativos foram frente a variações de ambiente, menos estáveis em contraste com os caracteres reprodutivos, que foram menos afetados pelo ambiente, ou seja, mais estáveis. Entretanto, alguns caracteres vegetativos, como a largura do pecíolo e o comprimento do limbo, foram considerados como relativamente estáveis. $\mathrm{O}$ autor ainda salienta que estes resultados em geral estão em concordância com aqueles obtidos por Goodman \& Paterniani (1969) para o milho. Resultados semelhantes (caracteres reprodutivos mais estáveis que os vegetativos), também foram encontrados por Martinez Wilches (1983) em amendoim. Com relação a mandioca, Pereira (1989) salienta que, apesar de serem menos estáveis que os caracteres florais e de fruto, os descritores de partes vegetativas desempenham um importante papel na sua taxonomia.

Jolliffe (1972 e 1973) comenta que, se um número grande de variáveis está disponível, freqüentemente, o resultado é pouco alterado se um subconjunto de variáveis é usado. É útil reduzir as variáveis redundantes, porque além de pouco informativas, elas contribuem para complicar a análise dos dados e não apresentam informação adicional.

Dessa forma, Jolliffe (1972 e 1973), avaliou com dados reais e simulados, oito métodos de descarte de variáveis, os quais foram divididos em três grupos. O primeiro consistiu de dois procedimentos que envolveram correlação múltipla. Quatro métodos basearam-se em componentes principais e dois em análises de agrupamento. $\mathrm{O}$ autor concluiu que todos os métodos deram resultados similares em rejeitar as variáveis redundantes, e a decisão por um deles deve ser tomada pela maior 
facilidade de aplicação ou rapidez de processamento. No caso de se utilizar componentes principais, os resultados são mais satisfatórios se o número de variáveis rejeitadas for igual ao número de componentes cuja variância é inferior a 0,70 . Este critério foi estabelecido para os casos em que os dados foram padronizados e, assim sendo, estimando-se os autovalores a partir da matriz de correlação.

Mardia et al. (1979) recomenda que, se uma análise de componentes principais é realizada a partir da matriz de correlação para todas as p variáveis, deve-se considerar o elemento do autovetor correspondente ao menor autovalor e rejeitar a variável com o maior coeficiente (valor absoluto). Este autor alerta, ainda, que quando o número de variáveis é muito elevado, uma forma mais realista é proceder ao descarte das variáveis de maior coeficiente, nos componentes cujo autovalor seja inferior a $\lambda=0,70$.

Pereira (1989), utilizando a análise de componentes principais e aplicando a metodologia de descarte de variáveis, apresentada por Jolliffe (1972 e 1973), na qual o número de descartes é igual ao número de componentes com autovalor inferior a 0,70, em estudo de 280 acessos do Banco Ativo de Germoplasma de Mandioca BAGM, da EMBRAPA, reduziu de 28 para 14 o número de descritores botânicoagronômicos, o que corresponde a uma redução de $50 \%$.

Daher (1993), estudando 60 acessos de um Banco Ativo de Germoplasma de capim-elefante, também utilizou a metodologia de Jolliffe (1972 e 1973). De um total de 22 caracteres medidos consistentemente durante três anos (1988, 1989 e 1990), conseguiu o descarte de 14 caracteres, ou seja, selecionou oito como sendo os mais importantes, para a determinação da divergência genética entre esses acessos. Para este estudo o autor concluiu sobre a eficiência do método utilizado no descarte dos caracteres de menor valor.

Cury (1993), no estudo de 30 acessos de mandioca (Manihot esculenta Crantz) descartou 6 descritores, dentre 20 , o que representa $30 \%$ do conjunto de descritores originais, quando adotou parcialmente a metodologia proposta por Jolliffe (1972 e 1973). O autor realizou o descarte das variáveis através da técnica dos componentes principais, descartando a variável com maior coeficiente do componente 
com menor autovalor em sucessivas análises, isto é, a cada descarte repetiu a análise considerando o novo subconjunto de variáveis. Observou também a matriz de correlações fenotipicas entre as variáveis, para auxiliar no descarte daquelas consideradas como redundantes. Neste caso o número de descartes não foi pré-fixado conforme Jolliffe (1972 e 1973), o qual levaria a descartar 13 variáveis, correspondendo a uma redução de $65 \%$.

Dias (1994), utilizou o critério de Jolliffe (1972 e 1973) complementado pelo procedimento utilizado por Cury (1993), no estudo de 26 clones de cacau. Descartou as variáveis que apresentaram os maiores elementos dos autovetores nos últimos componentes. A cada variável descartada refez a análise para novamente descartar aquela com maior elemento do autovetor. Esse processo de descarte sucessivo foi repetido até não ser mais possível discriminar os maiores elementos dos autovetores e/ou pela inconsistência em descartar variáveis não redundantes. Para um conjunto originalmente formado por 13 variáveis foram descartadas quatro, ou seja, cerca de $31 \%$, percentual semelhante ao obtido por Cury (1993). No caso de se utilizar a metodologia de Jolliffe (1972 e 1973) seriam descartadas 10 das 13 variáveis, o que equivale a cerca de $76 \%$.

Bedigian et al. (1986), no estudo da variabilidade morfológica de 353 acessos de gergelim, selecionaram 32 caracteres entre os 96 inicialmente considerados, usando um método sistemático para reduzir o número de variáveis. Os caracteres invariantes foram removidos por não contribuirem com a análise multivariada. $O$ coeficiente de correlação de Pearson entre caracteres que apresentaram valores acima de 0,60 foram reavaliados, permanecendo aqueles com maior significado biológico. Finalmente a análise de fator permitiu reduzir o número dos caracteres originais para um conjunto que contribuísse com mais informação.

Beale et al. (1967), utilizaram como procedimentos estatísticos para realizar o descarte de variáveis a análise de regressão e a análise de interdependência, na qual esta última, considera todas as variáveis descartadas como variáveis dependentes e maximiza o coeficiente de correlação múltipla mínimo entre as variáveis selecionadas e as 
descartadas, sendo utilizado a análise de componentes principais como solução aproximada deste problema.

Estas técnicas de seleção de variáveis, abordadas até o momento estão relacionadas com técnicas multivariadas, na literatura encontram-se outras técnicas estatísticas para uma seleção prévia de caracteres. Assim, Hussaini et al. (1977), descartaram 11 caracteres dentre os 29 inicialmente considerados, selecionando aqueles cuja relação $\sigma_{\text {ent }}^{2} /\left(\sigma_{e}^{2}+\sigma_{\text {rep }}^{2}\right)$ fosse maior ou igual a um, em que $\sigma_{\text {ent }}^{2}$ é o valor estimado do componente de variância devido a diferenças entre acessos; $\sigma_{\text {rep }}^{2}$ é o valor estimado do componente de variância devido a diferenças entre repetições e $\sigma_{\mathrm{e}}^{2}$ é o valor estimado do componente de variância residual. No trabalho de Martinez Wilches (1983), dentre os 31 caracteres considerados inicialmente, 13 foram selecionados de acordo com a razão $r=\sigma_{v}^{2} /\left(\sigma_{1}^{2}+\sigma_{v v}^{2}\right) \geq 1$, em que $\sigma_{v}^{2}, \sigma_{1}^{2}, \sigma_{v 1}^{2}$ são os valores estimados dos componentes de variância de variedades, localidades e da interação variedades $\mathrm{x}$ localidades, respectivamente.

Não foram encontrados trabalhos a respeito de seleção de variáveis em germoplasma do gênero Paspalum, que viessem a contribuir com esta revisão de literatura. 


\section{MATERIAL E MÉTODOS}

\subsection{Localização do Germoplasma, Clima e Solo}

O Centro de Pesquisa de Pecuária do Sudeste (CPPSE/EMBRAPA) mantém uma coleção viva das espécies do gênero Paspalum, com prioridade às pertencentes ao grupo Plicatula. Atualmente a coleção contêm 216 acessos oriundos de várias localidades do Continente Americano, principalmente do sul da América do Sul.

Esta coleção está sendo preservada na Fazenda Canchim, base fisica do CPPSE/EMBRAPA, localizada no município São Carlos, SP, a $22^{\circ} 01^{\prime}$ de latitude Sul, $47^{\circ} 53^{\prime}$ de longitude Oeste e altitude de 856 metros. O clima é do tipo $\mathrm{Cw}$ na Classificação de Köppen, ou seja subtropical com inverno seco e verão quente/úmido. O solo onde os acessos foram mantidos foi latossolo vermelho-amarelo álico, cujas características fisicas e químicas estão apresentadas na Tabela 1. 







\subsection{Material e Delineamento Experimental}

O presente estudo utilizou uma amostra de 27 acessos do gênero Paspalum, pertencentes ao grupo Plicatula, sendo cinco da espécie de P.guenoarum e 22 da espécie P.plicatulum. A identificação e procedência desses acessos encontram-se no Apêndice - Tabela 1.

As caracterizações botânico-agronômicas foram realizadas em três campos no delineamento experimental em blocos ao acaso com três repetições. A primeira repetição de cada campo foi utilizada para avaliação dos caracteres vegetativos e reprodutivos, sendo que as outras duas foram utilizadas para avaliação agronômica. As parcelas experimentais foram de $5 \mathrm{m \times} 2 \mathrm{~m}$ e as mudas espaçadas entre si de $0,5 \mathrm{mx}$ $0,5 \mathrm{~m}$, com área útil de $4 \mathrm{~m} \times 1 \mathrm{~m}$, constituida pelas duas fileiras centrais.

Desta amostra, os campos 1 e 2 contaram com 20 acessos. A avaliação agronômica foi realizada em quatro cortes sucessivos, sendo que das associações dos quatro cortes obteve-se a avaliação anual, dos dois primeiros cortes a avaliação de inverno (período de precipitação mínima - época das secas), e dos dois últimos a avaliação de verão (período de precipitação máxima - época das águas).

O campo 3 contou com 7 acessos (acessos número 5 e do número 22 ao 27), e sua avaliação agronômica anual procedeu-se como citado acima. A avaliação de inverno foi a associação dos cortes um e quatro e a avaliação de verão foi a associação dos cortes dois e três.

Foram utilizadas como testemunhas cultivares das espécies Brachiaria decumbens, Andropogon gayamus (campos 1,2 e 3), Paspalum notatum (campos 2 e 3) e Choris gayana - capim rhodes (campo 3). 


\subsection{Descritores Botânico-Agronômicos Avaliados}

Os caracteres botânico-agronômicos pertencentes aos acessos são denominados descritores. A caracterização morfológica dos acessos foi realizada através da avaliação dos descritores reprodutivos na época da floração, os vegetativos na época de maior desenvolvimento vegetativo (janeiro/fevereiro) e os descritores agronômicos nas fases de realização dos cortes. Os dados foram coletados pelo CPPSE/EMBRAPA em 1995.

O conjunto de descritores é dado a seguir :

\section{A) Parte Reprodutiva}

Os caracteres (de A a G) foram avaliados por notas, conforme segue:

A. Pilosidade do escapo (PE)

1 - glabro

2 - piloso

3 - sem escapo

B. Pilosidade do eixo floral (PEF)

1 - sem eixo floral

2 - glabro

3 - pêlo nos nós

4 - pêlo em toda extensão

C. Pilosidade do rácemo (PR)

1 - glabro

2 - pêlo nos nós

3 - pêlo na base

4 - pêlo em toda extensão 
5 - sem rácemo

D. Pilosidade da espigueta (PES)

1 - glabro

2 - piloso

3 - sem espigueta

E. Disposição do rácemo no eixo floral (DREF)

1 - opostos

2 - alternos

3 - alternos helicoidais

4 - opostos cruzados

5 - sem rácemo

F. Época de florescimento (EFL)

00-Sem flor

01- Janeiro

02- Fevereiro

03- Março

04- Abril

05- Maio

06- Junho

07- Julho

08- Agosto

09- Setembro

10- Outubro

11- Novembro

12- Dezembro 
G. Época de maturação (EM)

00- Sem fruto

01- Janeiro

02- Fevereiro

03- Março

04- Abril

05- Maio

06- Junho

07- Julho

08- Agosto

09- Setembro

10- Outubro

11- Novembro

12-Dezembro

H. Comprimento do escapo, em centímetros (CE): é a distância do último nó da haste reprodutiva até o início do eixo floral.

I. Comprimento do eixo floral, em centímetros (CEF): é a distância que vai do início do eixo floral até o ápice da planta.

Para o valor dos três descritores seguintes foi considerada a média de três plantas:

J. Número médio de rácemo por inflorescência (NMRI).

L. Número médio de pedicelos por rácemo (NMPR).

M. Comprimento médio do rácemo mais longo, em centímetros (CMRML). 
Para avaliar os descritores $\mathrm{N}$ e $\mathrm{O}$ foi considerado a média de três sementes:

N. Comprimento médio da semente, em milímetros (CMS).

O. Largura média da semente, em milímetros (LMS).

P. Número médio de sementes em 1 grama (NMS): tomou-se o peso de 1 grama de sementes e em seguida fez-se a contagem. Foram utilizadas duas amostras para a obtenção do valor desse descritor.

\section{B) Parte Vegetativa}

Os caracteres A e B foram avaliados com base na média de três plantas.

A. Número médio de entrenós (NMEN): usou-se a haste reprodutiva, não se considerando o eixo floral como entrenó.

B. Comprimento médio dos entrenós, em centímetros (CMEN): é a distância entre duas inserções (nós) da haste reprodutiva.

C. Altura média das plantas, em centímetros (AMP):

$\mathrm{AMP}=($ NMEN $\times$ CMEN $)$

Aos caracteres seguintes (de $\mathrm{D}$ a $\mathrm{O}$ ) foram dadas notas, conforme exposto:

D. Distribuição dos pêlos no limbo foliar (DIPLF)

1 - glabro (sem pêlo)

2 - pêlos nas margens

3 - pêlos na face dorsal

4 - pêlos na face ventral

5 - pêlos nas duas faces

6 - pêlo na base, próximo à lígula 
E. Densidade dos pêlos no limbo foliar (DEPLF)

1 - ausente

2 - pouco

3 - médio

4 - muito

F. Comprimento dos pêlos no limbo foliar (COPLF)

1 - ausente

2 - curto

3 - médio

4 - longo

G. Distribuição dos pêlos nas bainhas (DIPB)

1 - glabro

2 - pêlos nas margens

3 - pêlos na base

4 - pêlos no ápice

5 - pêlos em toda extensão

H. Densidade dos pêlos nas bainhas (DEPB)

1 - ausente

2 - pouco

3 - médio

4 - muito

I. Comprimento dos pêlos nas bainhas (COPB)

$$
\begin{aligned}
& 1 \text { - ausente } \\
& 2 \text { - curto } \\
& 3 \text { - médio }
\end{aligned}
$$


4 - longo

J. Densidade dos pêlos nos nós (DEPN)

1 - ausente

2 - pouco

3 - médio

4 - muito

L. Comprimento dos pêlos nos nós (COPN)

1 - ausente

2 - curto

3 - médio

4 - longo

M. Distribuição dos pêlos nos entrenós (DIPEN)

1 - glabro

2 - pêlos em toda extensão

N. Densidade dos pêlos nos entrenós (DEPEN)

1 - ausente

2 - pouco

3 - médio

4- muito

O. Comprimento dos pêlos nos entrenós (COPEN)

1 - ausente

2 - curto

3 - médio

4 - longo 
Foi tomada a média de três plantas para os caracteres seguintes (de $\mathrm{P}$ a V):

P. Comprimento médio da lâmina foliar, em centímetros (CMLF): foi feita a medição das folhas maiores, da lígula ao ápice da folha, as quais já tinham atingido seu crescimento máximo.

Q. Largura média da lâmina foliar da base, em centímetros (LMLFBASE).

R. Largura média da lâmina foliar do meio, em centímetros (LMLFMEIO).

S. Comprimento médio da bainha, em centímetros (CMB): para esta medição usou-se a bainha da folha maior.

T. Largura média da base da bainha, em centímetros (LMBBASE).

U. Largura média do meio da bainha, em centímetros (LMBMEIO).

V. Largura média do ápice da bainha, em centímetros (LMBAPICE).

X. Comprimento da haste reprodutiva, em centímetros (CHR): é a distância que vai do colo da planta até o ápice do eixo floral.

\section{C) Parte Agronômica}

\section{C.1) Descritores Agronômicos - Avaliação Anual}

A. Porcentagem média de matéria seca (PORMSANO): é a somatória dos percentuais de cada corte realizado no ano, dividido pelo número de cortes. 
B. Produção total de matéria seca ( $\mathrm{kg} / \mathrm{ha})$ (PRMSANO): é a somatória da produção de matéria seca de cada corte realizado no ano.

C. Porcentagem média de proteína bruta na matéria seca (PPMSANO): é a somatória dos percentuais de cada corte realizado no ano, dividido pelo número de cortes.

D. Porcentagem média de fibra em detergente neutro (FDNANO): é a somatória dos percentuais de cada corte realizado no ano, dividido pelo número de cortes.

E. Porcentagem média de digestibilidade "in vitro" (DIVANO): é a somatória dos percentuais de cada corte realizado no ano, dividido pelo número de cortes.

F. Nota média de desenvolvimento vegetativo (NOTANO): é a somatória das notas de cada corte realizado no ano, dividido pelo número de cortes.

Nota de desenvolvimento vegetativo: avaliação fenotípica realizada antes de cada corte através de uma escala de nota (0: planta morta a 5: planta com elevado desenvolvimento vegetativo).

G. Rebrota média (REBROAN): é a somatória das rebrotas de cada corte realizado no ano, dividido pelo número de cortes.

Rebrota: avaliação feita através de uma escala de nota 30 dias após o corte $(0$ : sem rebrota a 5: rebrota vigorosa).

\section{C.2) Descritores Agronômicos - Avaliação de Inverno}

A. Porcentagem média de matéria seca (PORMSINV): é a somatória dos percentuais de cada corte realizado no inverno (época das secas), dividido pelo número de cortes. 
B. Produção total de matéria seca ( $\mathrm{kg} / \mathrm{ha}$ ) (PRMSINV): é a somatória da produção de matéria seca de cada corte realizado no inverno.

C. Porcentagem média de proteina bruta na matéria seca (PPMSINVE): é a somatória dos percentuais de cada corte realizado no inverno, dividido pelo número de cortes.

D. Porcentagem média de fibra em detergente neutro (FDNINVER): é a somatória dos percentuais de cada corte realizado no inverno, dividido pelo número de cortes.

E. Porcentagem média de digestibilidade "in vitro" (DIVINVER): é a somatória dos percentuais de cada corte realizado no inverno, dividido pelo número de cortes.

F. Nota média de desenvolvimento vegetativo (NOTAINV): é a somatória das notas de cada corte realizado no inverno, dividido pelo número de cortes.

G. Rebrota média (REBROIN): é a somatória das rebrotas de cada corte realizado no inverno, dividido pelo número de cortes.

* C.3) Descritores Agronômicos - Avaliação de Verão

A. Porcentagem média de matéria seca (PORMSVER): é a somatória dos percentuais de cada corte realizado no verão (época das águas), dividido pelo número de cortes.

B. Produção total de matéria seca ( $\mathrm{kg} / \mathrm{ha}$ ) (PRMSVER): é a somatória da produção de matéria seca de cada corte realizado no verão. 
C. Porcentagem média de proteína bruta na matéria seca (PPMSVER): é a somatória dos percentuais de cada corte realizado no verão, dividido pelo número de cortes.

D. Porcentagem média de fibra em detergente neutro (FDNVERAO): é a somatória dos percentuais de cada corte realizado no verão, dividido pelo número de cortes.

E. Porcentagem média de digestibilidade "in vitro" (DIVERAO): é a somatória dos percentuais de cada corte realizado no verão, dividido pelo número de cortes.

F. Nota média de desenvolvimento vegetativo (NOTAVER): é a somatória das notas de cada corte realizado no verão, dividido pelo número de cortes.

G. Rebrota média (REBROVER): é a somatória das rebrotas de cada corte realizado no verão, dividido pelo número de cortes.

Todas as características reprodutivas, vegetativas e agronômicas foram avaliadas de acordo com padrões estabelecidos pelo CPPSE/EMBRAPA.

\subsection{Metodologias Estatísticas}

\subsubsection{Análise de Componentes Principais}

A metodologia da análise de componentes principais encontra-se detalhadamente descrita nos livros de Morrison (1976), Mardia et al. (1979) e Johnson \& Wichern (1982). 
A técnica de componentes principais consiste em transformar as $p$ variáveis originais $X_{1}, X_{2}, \ldots, X_{p}$, contidas no vetor

$$
X^{\prime}=\left(X_{1}, X_{2}, \ldots, X_{p}\right)
$$

mediante uma matriz ortogonal (matriz dos elementos dos autovetores), em $\mathrm{p}$ novas variáveis $Y_{1}, Y_{2}, \ldots, Y_{p}$ (componentes principais), contidas no vetor

$$
\mathbf{Y}^{\prime}=\left(\mathrm{Y}_{1}, \mathrm{Y}_{2}, \ldots, \mathrm{Y}_{\mathrm{p}}\right)
$$

não correlacionadas entre si.

Formalizando este conceito tem-se a seguinte definição:

Se $\mathrm{X}$ é um vetor aleatório com média $\mu$ e matriz de covariância $\Sigma$, simétrica, positiva semi definida, então a transformação do componente principal é dada por:

$$
\mathbf{X} \rightarrow \mathbf{Y}=\mathbf{B}^{\prime}(\mathbf{X}-\mu)
$$

em que B é uma matriz ortogonal, a variância do componente principal (Y) é dada por:

$$
\operatorname{Var}(\mathbf{Y})=\mathbf{B}^{\prime} \mathbf{\Sigma} \mathbf{B}=\Lambda,
$$

sendo $\Lambda$ uma matriz diagonal que exibe as raízes características de $\Sigma$, ou seja:

$$
\Lambda=\operatorname{diag}\left\{\lambda_{1}, \lambda_{2}, \Lambda, \lambda_{\mathrm{p}}\right\}, \lambda_{1} \geq \lambda_{2} \geq \Lambda \geq \lambda_{\mathrm{p}} \geq 0
$$

Cabe ressaltar que não se perde a generalidade se se supõe o vetor de médias como vetor nulo.

TEOREMA 1: Se $\mathbf{X} \sim(\phi, \Sigma)$ e $\mathbf{Y}$ definido como na igualdade (1), tem-se:
a) $E\left(Y_{i}\right)=0$;
b) $\operatorname{Var}\left(Y_{i}\right)=\lambda_{i} ; \operatorname{com} i=1,2, \ldots, p$
c) $\operatorname{Cov}\left(Y_{i}, Y_{j}\right)=0$, para $i \neq j$;
d) $\operatorname{Var}\left(Y_{1}\right) \geq \operatorname{Var}\left(Y_{2}\right) \geq \ldots \geq \operatorname{Var}\left(Y_{p}\right) \geq 0$;
e) $\sum_{\mathrm{i}=1}^{\mathrm{p}} \operatorname{Var}\left(\mathrm{Y}_{\mathrm{i}}\right)=\sum_{\mathrm{i}=1}^{\mathrm{p}} \lambda_{\mathrm{i}}=\operatorname{tr}(\Sigma)$;
f) $\prod_{i=1}^{p} \operatorname{Var}\left(Y_{i}\right)=\prod_{i=1}^{p} \lambda_{i}=|\Sigma|$ 


\subsubsection{Obtenção dos Componentes Principais}

$\mathrm{Na}$ prática, o problema estatístico consiste, fundamentalmente, em estimar os coeficientes de ponderação das variáveis em cada componente e a variância a elas associada.

Morrison (1976), demonstra que a variância associada a cada componente é estimada pelas raizes características da matriz $\mathbf{S}$ (matriz de covariâncias amostral; sendo $\mathbf{S}$ um estimador de $\Sigma$ ), e os coeficientes de ponderação das variáveis pelos elementos dos vetores característicos (ou autovetores) correspondentes.

O primeiro componente principal é a combinação linear

$$
Y_{1}=b_{11} X_{1}+b_{21} X_{2}+\ldots+b_{p 1} X_{p}=\mathbf{b}_{1} X
$$

das variáveis originais com a maior variância.

Sua variância na forma matricial é dada por :

$$
\operatorname{Var}\left(Y_{1}\right)=\mathbf{b}_{1} \mathbf{S ~ b}_{1}
$$

Portanto, para obter o primeiro componente principal deve-se determinar o vetor $\mathbf{b}_{1}$, de tal forma que a variância de $Y_{1}$ seja maximizada, impondo-se restrição no conjunto de soluções de $\mathbf{b}_{1}$ por meio de

$$
\mathbf{b}^{\prime}{ }_{1} \mathbf{b}_{1}=1
$$

Expressando a variância de $Y_{1}$ pela função $G_{1}$ e incorporando a restrição pelo multiplicador $\lambda$ de Lagrange, tem-se:

$$
\mathrm{G}_{1}=\mathbf{b}{ }_{1} \mathbf{S} \mathbf{b}_{1}-\lambda\left(\mathbf{b}^{\prime}{ }_{1} \mathbf{b}_{1}-1\right)
$$

Diferenciando $G_{1}$ em relação a $\mathbf{b}_{1}$ e igualando a zero, obtém-se:

$$
\begin{gathered}
\frac{\delta \mathrm{G}_{1}}{\delta \mathbf{b}_{1}}=2 \mathbf{S} \mathbf{b}_{1}-2 \lambda \mathbf{b}_{1}=0 \\
(S-\lambda \mathbf{I}) \mathbf{b}_{1}=0
\end{gathered}
$$

A solução do sistema deve ser tal que $\mathbf{b}_{1} \neq \phi$ ( solução não trivial). Dessa forma é necessário que o determinante de $(\mathbf{S}-\lambda \mathbf{I})$ seja nulo, isto é:

$$
|\mathbf{S}-\lambda \mathbf{I}|=0
$$


sendo que o lado esquerdo dessa igualdade é um polinômio de grau p em $\lambda, \mathrm{P}(\lambda)$, chamado polinômio característico. Resolvendo esse polinômio encontram-se p raizes, $\lambda_{1}$, $\lambda_{2}, \ldots, \lambda_{\mathrm{p}}$, denominadas autovalores, valores próprios ou raízes características de $\mathbf{S}$.

Para determinar qual das $\mathrm{p}$ raízes características deve ser usada, prémultiplica-se o sistema de equações ( 2 ) por $\mathbf{b}_{1}$, , e usando-se a restrição

$$
\begin{gathered}
\mathbf{b}_{1} \mathbf{b}_{1}=1, \text { tem-se: } \\
\mathbf{b}_{1}(\mathbf{S}-\lambda \mathbf{I}) \mathbf{b}_{1}=0 \\
\mathbf{b}_{1} \mathbf{S}_{\mathbf{b}} \mathbf{b}_{1}-\lambda \mathbf{b}_{1} \mathbf{b}_{1}=0 \\
\operatorname{logo}, \mathbf{b}_{1}{ }_{1} \mathbf{S} \mathbf{b}_{1}=\lambda
\end{gathered}
$$

Dessa forma a,

$$
\operatorname{Vâr}\left(Y_{1}\right)=\operatorname{Vâr}\left(\mathbf{b}^{\prime}{ }_{1} \mathbf{X}\right)=\mathbf{b}_{1}{ }_{1} \mathbf{S} \mathbf{b}_{1}=\lambda
$$

que, para ser máxima, requer o maior autovalor de $S$, ou seja $\lambda_{1}$, incorporado na equação (2). Assim,

$$
\left(\mathbf{S}-\lambda_{1} \mathbf{I}\right) \mathbf{b}_{1}=0 \text {, }
$$

cuja solução sujeita à restrição

$$
\mathbf{b}^{\prime}{ }_{1} \mathbf{b}_{1}=1
$$

fornecerá o autovetor de norma $1, \mathbf{b}_{1}$, associado a $\lambda_{1}$.

O segundo componente principal é a combinação linear

$$
\mathrm{Y}_{2}=b_{12} \mathrm{X}_{1}+\mathrm{b}_{22} \mathrm{X}_{2}+\ldots+\mathrm{b}_{\mathrm{p} 2} \mathrm{X}_{\mathrm{p}}=\mathbf{b}_{2}{ }_{2} \mathrm{X}
$$

normalizado segundo

$$
\mathbf{b}_{2}^{\prime} \mathbf{b}_{2}=1
$$

que tem a maior variância entre todas as combinações lineares não correlacionadas com $\mathrm{Y}_{1}$.

Sua variância na forma matricial é dada por:

$$
\operatorname{Var}\left(\mathrm{Y}_{2}\right)=\mathbf{b}_{2}{ }_{2} \mathbf{S} \mathbf{b}_{2}
$$

$\mathrm{Na}$ obtenção do vetor $\mathbf{b}_{2}$, de tal forma que a variância de $Y_{2}$ seja maximizada, impõem-se as restrições,

$$
\mathbf{b}_{2}^{\prime} \mathbf{b}_{2}=1 \text { e } \mathbf{b}_{2}^{\prime} \mathbf{b}_{1}=\mathbf{b}^{\prime} \mathbf{b}_{2}=0 \text {. }
$$


A restrição

$$
\mathbf{b}_{2} \mathbf{b}_{2}=1
$$

é necessária para garantir a unicidade de $\mathbf{b}_{2}$, enquanto que

$$
\mathbf{b}_{1}^{\prime} \mathbf{b}_{2}=0
$$

faz com que $Y_{1}$ e $Y_{2}$ sejam ortogonais, ou seja, garante que $Y_{1}$ e $Y_{2}$ sejam variáveis não correlacionadas.

De acordo com o método de Lagrange, forma-se a função:

$$
\mathrm{G}_{2}=\mathbf{b}_{2}{ }_{2} \mathbf{S} \mathbf{b}_{2}-\lambda\left(\mathbf{b}_{2}^{\prime} \mathbf{b}_{2}-1\right)-h\left(\mathbf{b}_{1}^{\prime} \mathbf{b}_{2}\right),
$$

sendo $\lambda \mathrm{e} h$ os multiplicadores de Lagrange.

Diferenciando em relação $\mathbf{a} \mathbf{b}_{2}$ e igualando a zero, encontra-se:

$$
\begin{aligned}
& \frac{\delta \mathrm{G}_{2}}{\delta \mathbf{b}_{2}}=2 \mathbf{S} \mathbf{b}_{2}-2 \lambda \mathbf{b}_{2}-\mathrm{h} \mathbf{b}_{1}=0 \\
& 2(\mathbf{S}-\lambda \mathbf{I}) \mathbf{b}_{2}-\mathrm{h} \mathbf{b}_{1}=0
\end{aligned}
$$

Pré-multiplicando a equação (3) por $\mathbf{b}_{1}{ }_{1}$ e lembrando que $\mathbf{b}^{\prime} \mathbf{b}_{\mathbf{2}}=0$ e $\mathbf{b}^{\prime}{ }_{1} \mathbf{b}_{1}=1$, obtémse:

$$
\begin{gathered}
2 \mathbf{b}_{1}{ }_{1} \mathbf{S} \mathbf{b}_{2}-2 \lambda \mathbf{b}_{1} \mathbf{b}_{2}-\mathrm{hb}{ }_{1}{ }_{1} \mathbf{b}_{1}=0 \\
\mathbf{b}^{\prime}{ }_{1} \mathbf{S} \mathbf{b}_{2}=\mathrm{h}
\end{gathered}
$$

Uma vez que $\mathbf{S}$ é simétrica, tem-se que:

$$
\mathbf{b}_{1}{ }_{1} \mathbf{S}=\lambda \mathbf{b}_{1}{ }_{1}
$$

então,

$$
\lambda \mathbf{b}^{\prime}{ }_{1} \mathbf{b}_{2}=h
$$

portanto,

$$
h=0
$$

Substituindo esse resultado na equação (3) obtém-se:

$$
(\mathbf{S}-\lambda \mathbf{I}) \mathbf{b}_{\mathbf{2}}=0
$$

Pré-multiplicando a equação (4) por b' 2 , e usando a restrição $\mathbf{b}_{2} \mathbf{b}_{\mathbf{2}}=1$, tem-se;

$$
\mathbf{b}_{2}^{\prime} \mathbf{S} \mathbf{b}_{2}-\lambda \mathbf{b}_{2}{ }_{2} \mathbf{b}_{2}=0
$$




$$
\mathbf{b}_{2} \mathbf{S ~}_{2}=\lambda
$$

Desse modo a,

$$
\operatorname{Vâr}\left(Y_{2}\right)=\operatorname{Vâr}\left(\mathbf{b}_{2}^{\prime} \mathbf{X}\right)=\mathbf{b}_{2}^{\prime} \mathbf{S} \mathbf{b}_{2}=\lambda
$$

que, para ser máxima, requer o segundo maior autovalor de $S$, ou seja, $\lambda_{2}$, substituído na equação (4). Assim (S- $\left.\lambda_{2} \mathbf{I}\right) \mathbf{b}_{2}=0$, cuja solução sujeita à restrição $\mathbf{b}_{2}^{\prime} \mathbf{b}_{2}=1$ dará o autovetor de norma $1, \mathbf{b}_{2}$, associado a $\lambda_{2}$.

Os demais componentes principais são encontrados de forma análoga ao processo apresentado, que pode ser resumido neste teorema:

TEOREMA 2: Seja o vetor aleatório $X$ de $\mathrm{p}$ componentes, com vetor de médias $\mu \mathrm{e}$ matriz de covariâncias $\Sigma$, simétrica, positiva semi definida.

Então existe uma transformação ortogonal

$$
\mathbf{Y}=\mathbf{B}^{\prime}\{\mathbf{X}-\mu\}=\left(\mathrm{Y}_{1}, \ldots, \mathrm{Y}_{\mathrm{p}}\right)
$$

tal que a matriz de covariâncias de $\mathrm{Y}$ é $\Lambda=\operatorname{diag}\left(\lambda_{\mathrm{i}}\right)$, com $\mathrm{i}=1, \ldots, \mathrm{p}$, sendo que $\lambda_{1} \geq \lambda_{2} \geq \Lambda \geq \lambda_{\mathrm{p}} \geq 0$, são autovalores da matriz $\Sigma$ e $\mathbf{b}_{\mathrm{i}}$ os autovetores associados, normalizados por $\mathbf{b}^{\prime} \mathbf{b}_{\mathbf{i}}=1$. A q+1-ésima coluna da matriz $\mathbf{B}, \mathbf{b}_{\mathbf{q}+1}$, satisfaz a condição de $\left(\Sigma-\lambda_{\mathbf{q}+1} \mathbf{I}\right) \mathbf{b}_{\mathbf{q}+1}=0$

e a combinação linear

$$
\mathrm{Y}_{\mathbf{q}+1}=\mathbf{b}_{\mathbf{q}+1}^{\prime} \mathbf{X}
$$

tem máxima variância entre todas as combinações lineares não-correlacionadas com $\left(Y_{1}, \ldots, Y_{q}\right)$.

Neste estudo, os autovalores e autovetores foram estimados a partir da matriz de correlações fenotípicas $\mathbf{R}$, isto é, todas as variáveis originais foram padronizadas, tal que tenham variância unitária. Segundo Morrison (1976), essa padronização dos dados é obtida por

$$
z_{i j}=\frac{x_{i j}-\bar{x}_{j}}{s_{j}}
$$

sendo que, 
$z_{i j}$ : é o valor observado padronizado da j-ésima variável no i-ésimo indivíduo, com $i=1,2, \ldots, n$ e $j=1,2, \ldots, p$;

$\mathrm{x}_{\mathrm{ij}}$ : é o valor observado da j-ésima variável no i-ésimo indivíduo, com $\mathrm{i}=1,2, \ldots, \mathrm{n}$ e $\mathrm{j}=1,2, \ldots, \mathrm{p}$;

$\overline{\mathrm{x}}_{\mathrm{j}}=\frac{1}{\mathrm{n}} \sum_{\mathrm{i}=1}^{\mathrm{n}} \mathrm{x}_{\mathrm{ij}}$, é a estimativa da média da j-ésima variável;

$\mathrm{s}_{\mathrm{j}}=\left[\frac{1}{\mathrm{n}-1} \sum_{\mathrm{i}=1}^{\mathrm{n}}\left(\mathrm{x}_{\mathrm{ij}}-\overline{\mathrm{x}}_{\mathrm{j}}\right)^{2}\right]^{\frac{1}{2}}$, é o desvio padrão da j-ésima variável;

$\mathrm{n}=$ número de observações;

$\mathrm{p}=$ número de variáveis.

Assim, tem-se : $\mathbf{R}=\mathbf{Z}^{\prime} \mathbf{Z}$, sendo $\mathbf{Z}$ a matriz dos dados padronizados.

\subsubsection{Importância Relativa de um Componente Principal}

Sabe-se que:

$$
\begin{gathered}
\operatorname{Var}\left(Y_{1}\right)=\lambda_{1} \\
\operatorname{Var}\left(Y_{2}\right)=\lambda_{2} \\
\vdots \\
\operatorname{Var}\left(Y_{p}\right)=\lambda_{p}
\end{gathered}
$$

logo,

$$
\sum_{j=1}^{p} \operatorname{Var}\left(Y_{j}\right)=\sum_{j=1}^{p} \lambda_{j}=\operatorname{traço~}(\mathbf{R})=p=\text { variação total }
$$

A importância relativa de um componente é avaliada pela porcentagem da variância total explicada pelo j-ésimo componente principal, ou seja, a importância de $\mathrm{Y}_{\mathrm{j}}$ é dada por: 


$$
\frac{\lambda_{j}}{\text { variação total }}=\frac{\lambda_{j}}{\sum_{j=1}^{p} \lambda_{j}}=\frac{\lambda_{j}}{\operatorname{traço(R)}}=\frac{\lambda_{j}}{p}
$$

Pode-se também calcular a variabilidade explicada pelos q primeiros componentes, por,

$$
\frac{\sum_{j=1}^{q} \lambda_{j}}{\operatorname{traço(R)}} \times 100 \%
$$

sendo $(\mathrm{q}<\mathrm{p}$ ). Quando poucos componentes explicam grande percentagem da variância total, conclui-se que a estrutura de associação entre as variáveis é muito forte.

\subsubsection{Seleção dos Descritores Botânico-Agronômicos}

Baseado no princípio de que a importância ou variância dos componentes principais decresce do primeiro para o último, tem-se que os últimos componentes são responsáveis pela explicação de uma fração muito pequena da variância total. Assim, a variável que domina (maior coeficiente) o componente de menor autovalor (em valor absoluto), deve ser a menos importante para explicar a variância total e portanto, passivel de descarte (Pereira, 1989).

Quando o tamanho da amostra, n, é menor que o número de variáveis $p,(n<p)$, corresponde que todos os $n$ pontos observados se encontrarão em um espaço menor que p-dimensional, ou seja, há uma degeneração no espaço multidimensional, dessa forma, a matriz de covariâncias amostral é singular. Isto vai refletir na análise dos autovalores, onde alguns de seus valores serão iguais a zero. Segundo Flury \& Riedwyl (1988), quando autovalores são iguais a zero devido a esta situação, eles não tèm interpretação significativa, uma vez que isto ocorre porque o número de observaçōes é 
insuficiente e, como regra básica a análise de componentes principais não deveria ser usada em tal caso.

Com isso, devido ao número pequeno de acessos disponiveis para este estudo ( $\mathrm{n}=27)$, e a grande quantidade de variáveis, optou-se por realizar uma análise de componentes principais para cada conjunto de variáveis. Desse modo, foi realizada uma análise de componentes principais para as 15 variáveis reprodutivas, uma para as 22 variáveis vegetativas e três para cada avaliação agronômica, isto é, uma análise para as sete variáveis referentes à avaliação anual, para as sete referentes à avaliação de inverno e para as sete referentes à avaliação de verão, a fim de se proceder à eliminação dos descritores redundantes.

Com a seleção dos caracteres a partir das cinco análises acima, foi feita uma análise de componentes principais com estes caracteres que foram selecionados, para se proceder a um novo descarte, totalizando, portanto, seis análises de componentes principais.

Adotou-se o critério de descartar a variável de maior coeficiente, em cada componente com autovalor menor que 0,70 , de acordo com as preposições de Jolliffe (1972 e 1973) e Mardia et al. (1979).

\subsubsection{Comparação dos Componentes Principais}

De acordo com Jolliffe (1973), pode-se fazer uma comparação dos componentes principais para os conjuntos de dados completo e reduzido, a fim de se verificar a eficiência do descarte. Como medida de similaridade entre um par particular dos componentes usa-se o coeficiente de correlação, denotado $r_{1}$. Para medida de similaridade entre dois conjuntos de componentes, ou seja, $\mathrm{Q}_{1}$, deve ser usada uma média 
ponderada dos $\mathrm{r}_{1}$ `s para os vários pares de componentes. $\mathrm{O}$ parâmetro $\mathrm{Q}_{1}$ é uma medida da similaridade entre componentes, para o conjunto dos dados completo e reduzido.

Para a obtenção dessas medidas de similaridade deve-se considerar o conjunto de dados completo contendo $\mathrm{p}$ variáveis, medidas em $\mathrm{n}$ indivíduos. A análise de componentes principais é realizada com a matriz de correlação $\mathbf{R}$, que fornecerá as correlações amostrais $r_{i j}$ entre cada par de variáveis $\left\{X_{i}, X_{j}\right\}$.

Do conjunto de dados completo, um componente principal genérico pode ser escrito como uma combinação linear das $\mathrm{p}$ variáveis, assim tem-se:

$$
Y_{i}=a_{1 i} X_{1}+a_{2 i} X_{2}+\ldots+a_{p i} X_{p}=a_{i}^{\prime} \mathbf{X}, \text { com } i=1,2, \ldots, p
$$

De maneira análoga, para o conjunto de dados reduzido, um componente principal genérico pode ser escrito como:

$$
W_{j}=b_{1 j} X_{1}+b_{2 j} X_{2}+\ldots+b_{p j} X_{p}=\mathbf{b}_{j}{ }_{j} X, \text { com } j=1,2, \ldots, p
$$

em que, os coeficientes a e $b$, são constantes, sendo nulos os valores de $b$ correspondentes às variáveis descartadas.

Desse modo, conforme apresentação de Jolliffe (1973), o coeficiente de correlação entre $Y_{i}$ e $W_{j}$, denotado $r_{1}$, é dado por:

$$
r_{1}=\frac{\left(\sum_{i=1}^{p} \sum_{j=1}^{p} a_{i} b_{j} r_{i j}\right)}{\left\{\left(\sum_{i=1}^{p} \sum_{j=1}^{p} a_{i} a_{j} r_{i j}\right)\left(\sum_{i=1}^{p} \sum_{j=1}^{p} b_{i} b_{j} r_{i j}\right)\right\}^{\frac{1}{2}}}
$$

Geralmente só os primeiros (m) componentes principais são de interesse para o conjunto de dados completo. Assim tem-se que:

$$
Q_{1}=\frac{\sum_{i=1}^{m} q_{i} r_{1}(j)}{\sum_{i=1}^{m} q_{i}}
$$


sendo:

- $r_{1}(j)$ : é o valor máximo de $r_{1}$, definido anteriormente, entre o i-ésimo componente para o conjunto de dados completo e algum componente para o conjunto de dados reduzido;

- $q_{i}$ : é a proporção da variação total explicada pelo i-ésimo componente no conjunto de dados completo.

As estimativas $r_{1}$ e $Q_{1}$ foram obtidas para cada categoria de caracteres (reprodutivos, vegetativos e agronômicos), e também na análise final em que foram reunidos os caracteres selecionados previamente.

\subsubsection{Análise da Variância Univariada}

Os dados referentes à avaliação agronômica foram submetidos a análise de variância univariada, com os seguintes objetivos:

a) avaliar a significância dos efeitos de tratamentos (acessos);

b) estimar erro experimental.

\subsubsection{Programas Computacionais Utilizados}

Utilizou-se o pacote estatístico SAS versão 6:

a.1) PROC PRINCOMP - este procedimento permite proceder a análise de componentes principais, que são usados para reduzir o número de variáveis e detectar relações lineares entre as variáveis;

a.2) PROC CORR - através deste procedimento pode-se calcular diversos tipos de coeficientes de correlação entre variáveis, como o coeficiente de correlação de Pearson e correlação de posto de Spearman quando os dados não apresentam uma natureza 
natureza paramétrica ou quando a normalidade não pode ser pressuposta com um certo grau de certeza;

a.3) PROC ANOVA - é utilizada quando se deseja obter análise de variância com aplicação do teste "F", para dados balanceados;

a.4) PROC GLM - é utilizada quando se deseja obter análise de variância com aplicação do teste "F", para dados balanceados, sendo mais indicado para dados desbalanceados; 


\section{RESULTADOS E DISCUSSÃO}

\subsection{Seleção de Descritores Botânico-Agronômicos}

Quando se dispõe de um número muito grande de descritores, é possivel que muitos deles sejam redundantes ou, em outras palavras, altamente correlacionados entre si. Neste caso torna-se útil a eliminação destes caracteres redundantes, uma vez que eles são pouco informativos, e contribuem para uma análise de dados mais trabalhosa, e não necessariamente mais precisa.

Visando otimizar o conjunto dos descritores botânico-agronômicos, procedeu-se à sua seleção de acordo com a metodologia já citada anteriormente.

\subsubsection{Seleção de Descritores Reprodutivos}

As médias e os desvios padrão relativos aos 15 descritores reprodutivos avaliados para 26 acessos encontram-se no Apêndice - Tabela 2. O acesso de código BRA-009181 não foi considerado nos cálculos por apresentar falhas na coleta dos dados.

As estimativas das variâncias de cada componente, e a porcentagem acumulada destas estimativas para os 15 componentes principais obtidos a partir dos 15 descritores encontram-se na Tabela 2. Observa-se que o primeiro componente concentrou $33,41 \%$ da variância total, o segundo $18,33 \%$, o terceiro $11,74 \%$ e o quarto $9,25 \%$. A variância acumulada pelos quatro primeiros componentes foi de $72,73 \% \mathrm{e}$, pelos seis primeiros componentes de $87,16 \%$. Os nove últimos componentes concentram relativamente pouco da variação, apenas $12,84 \%$. 
Pelo critério adotado, descartaram-se 9 descritores (Tabela 2), que por ordem foram: CMRML, PE, EM, CMS, NMPR, NMRI, NMS, PES E PR.

Tabela 2 - Estimativas das variâncias dos componentes (autovalor $\lambda_{j}$ ), porcentagem acumulada das estimativas das variâncias (\%) dos 15 descritores reprodutivos avaliados em 26 acessos das espécies P.guenoarum e P.plicatulum - 1996.

\begin{tabular}{ccc}
\hline Componentes & $\begin{array}{r}\text { Variâncias dos } \\
\text { Componentes }\left(\lambda_{j}\right)\end{array}$ & $\begin{array}{c}\text { Porcentagens Acumuladas } \\
(\%)\end{array}$ \\
\hline 1 & 5,0107 & 33,41 \\
3 & 2,7496 & 51,74 \\
4 & 1,7611 & 63,48 \\
5 & 1,3888 & 72,73 \\
6 & 1,1190 & 80,19 \\
7 & 1,0451 & 87,16 \\
8 & 0,5836 & 91,05 \\
9 & 0,4215 & 93,86 \\
10 & 0,3135 & 95,95 \\
11 & 0,2539 & 97,65 \\
12 & 0,1393 & 98,57 \\
13 & 0,1016 & 99,25 \\
14 & 0,0607 & 99,66 \\
15 & 0,0417 & 99,93 \\
\hline
\end{tabular}

Assim, com a utilização desta metodologia foi possivel promover uma redução de $60 \%$ dos 15 descritores, inicialmente considerados. Pereira (1989) e Daher 
(1993), obtiveram uma redução de $50 \%$ e $63 \%$ do conjunto de descritores originais com mandioca e capim elefante, respectivamente.

As Tabelas 3, 4 e 5 apresentam as estimativas das correlações entre os descritores dentro do grupo selecionado, entre os descritores selecionados e descartados e entre os descritores dentro do grupo descartado, respectivamente.

A significância das estimativas das correlações de Pearson para as variáveis reprodutivas e vegetativas foram obtidas a partir do coeficiente de correlação de posto de Spearman.

Tabela 3 - Estimativas dos coeficientes de correlação entre os descritores das espécies P. guenoarum e P.plicatulum dentro do grupo selecionado - 1996.

\begin{tabular}{lcccccc}
\hline & \multicolumn{5}{c}{ Descritores Selecionados } \\
\cline { 2 - 7 } $\begin{array}{l}\text { Descritores } \\
\text { Selecionados }\end{array}$ & PEF & CE & CEF & DREF & EFL & LMS \\
\hline PEF & 1,000 & $-0,097$ & 0,048 & 0,056 & 0,056 & $-0,092$ \\
CE & & 1,000 & $-0,391^{*}$ & $-0,187$ & $-0,004$ & $0,383^{*}$ \\
CEF & & 1,000 & 0,432 & $-0,391$ & $-0,026$ \\
DREF & & & 1,000 & $-0,256$ & 0,069 \\
EFL & & & & 1,000 & $-0,358$ \\
LMS & & & & & 1,000 \\
\hline * significativos ao nível de 0,05 de probabilidade, a significância foi obtida a partir do \\
coeficiente de correlação de posto (Spearman).
\end{tabular}

Notou-se que, entre os descritores dentro do grupo selecionado, há duas combinações de pares de variáveis cujos coeficientes de correlação se mostraram estatisticamente significativos (Tabela 3). Além disso essas correlações podem ser consideradas baixas, implicando que estes descritores selecionados não são redundantes, ou seja, não são altamente correlacionados entre si.

Por outro lado, esta mesma situação não se apresentou para as Tabelas 4 e 5 , em que se observaram 15 e 5 combinações de pares de variáveis que apresentaram 
valores estatisticamente significativos, respectivamente, sendo que a magnitude da maior parte dessas combinações pode ser considerada alta.

Estes resultados demonstraram que o método de descarte dos caracteres empregados, foi eficiente na seleção de descritores discriminantes.

Tabela 4 - Estimativas dos coeficientes de correlação entre os descritores selecionados (horizontal) e descartados (vertical) para os 15 desritores reprodutivos das espécies P.guenoarum e P.plicatulum - 1996.

\begin{tabular}{lcccccc}
\hline & \multicolumn{6}{c}{ Descritores Selecionados } \\
\cline { 2 - 7 } $\begin{array}{l}\text { Descritores } \\
\text { Descartados }\end{array}$ & PEF & CE & CEF & DREF & EFL & LMS \\
\hline PE & $0,609^{* *}$ & $-0,474^{*}$ & $-0,416^{*}$ & $-0,149$ & 0,062 & $-0,036$ \\
PR & 0,145 & $-0,052$ & 0,128 & $-0,318$ & 0,139 & $-0,088$ \\
PES & $-0,006$ & $-0,324$ & $0,392^{*}$ & 0,272 & 0,171 & $-0,020$ \\
NMRI & 0,010 & 0,091 & $0,511^{*}$ & $0,466^{*}$ & $-0,439$ & 0,001 \\
NMPR & $-0,067$ & 0,237 & $0,600^{* *}$ & 0,233 & $-0,446$ & 0,295 \\
CMRML & $-0,007$ & 0,093 & $0,801^{* *}$ & 0,323 & $-0,463$ & 0,192 \\
EM & 0,050 & 0,021 & $-0,504^{* *}$ & $-0,190$ & $0,807^{* *}$ & $-0,619^{*}$ \\
CMS & $-0,068$ & $0,363^{* *}$ & 0,441 & 0,034 & $-0,527$ & $0,600^{* *}$ \\
NMS & $-0,042$ & $-0,547^{* *}$ & 0,015 & 0,002 & 0,266 & $-0,703^{* *}$ \\
\hline
\end{tabular}

${ }^{*},{ }^{* *}$ significativos ao nível de 0,05 e $0,01 \%$ de probabilidade, respectivamente, a significância foi obtida a partir do coeficiente de correlação de posto (Spearman). 


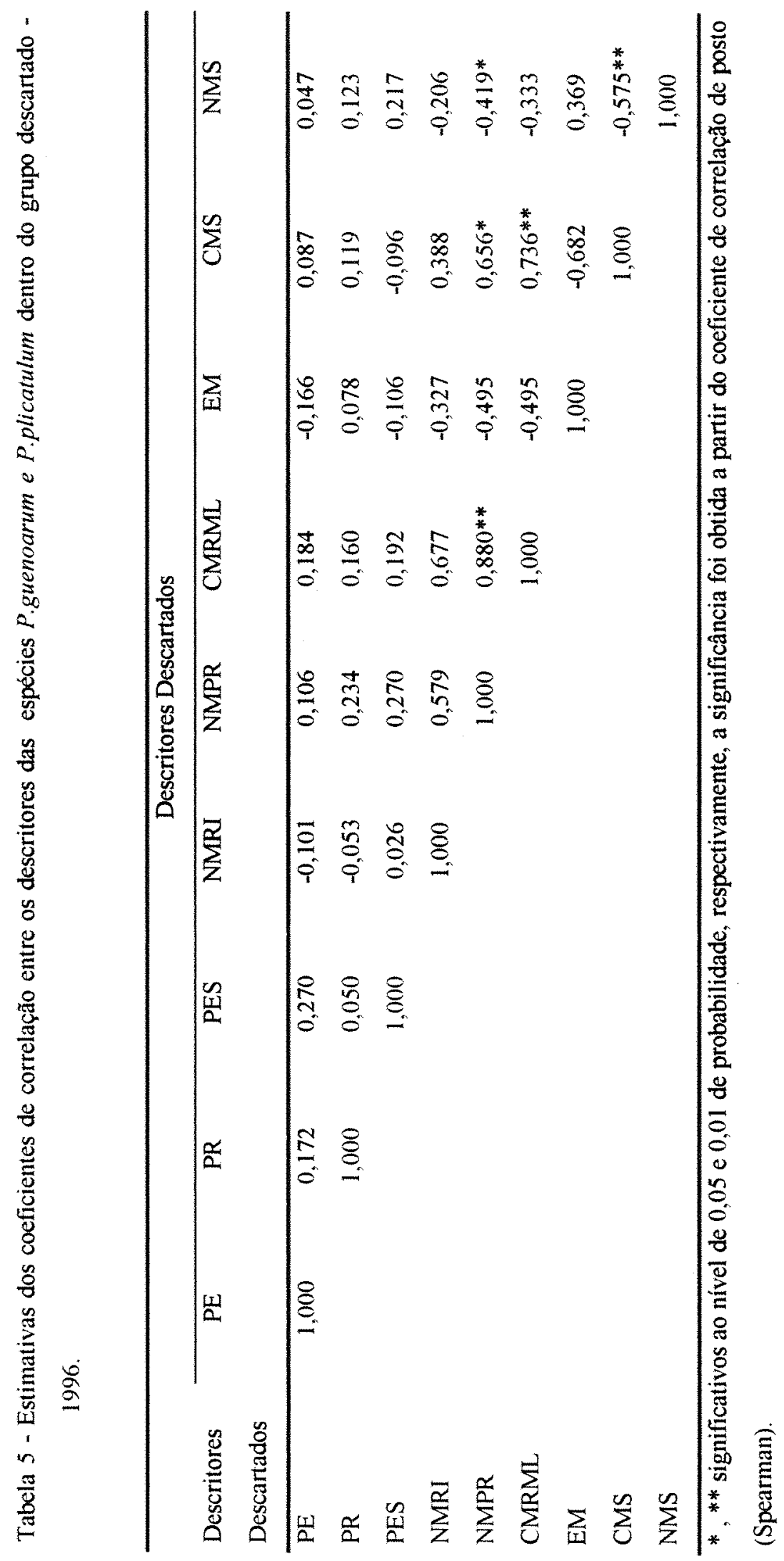


Dentre os descritores selecionados, os que apresentam o maior número de coeficientes de correlação significativos com os descritores descartados foram $\mathrm{CE}$ ( 3 combinações), CEF (6 combinações), e LMS (3 combinações) (Tabela 4). Estes resultados estão de acordo com a idéia apresentada anteriormente, de que os descritores descartados, por explicarem o mesmo fenômeno que os descritores selecionados, são redundantes, sendo, portanto, de interesse a sua eliminação.

Observando-se a Tabela 4 e as estimativas das correlações entre os 15 descritores (Apêndice - Tabela 3), verificou-se que o descritor PR não está correlacionado com nenhum dos demais. Este foi o último a ser descartado quando se adotou como critério de descarte as variáveis com o maior autovetor em componentes com autovalores inferiores a 0,70 . Sendo um pouco flexível e adotando-se um valor inferior a 0,60 para os autovalores, este descritor também poderia ser selecionado. Cabe ressaltar que os comentários feitos sobre as Tabelas 3,4,e 5, permanecem inalterados com a inclusão desse descritor dentro do grupo selecionado.

\subsubsection{Comparação dos Componentes Principais de Descritores Reprodutivos}

Segundo Jolliffe (1973), há três critérios pelos quais a semelhança entre componentes a partir de dados completos e reduzidos pode ser avaliada. O primeiro relaciona-se com os valores totais dos coeficientes de correlação $r_{1}$ e $Q_{1}$, o segundo é verificar se os componentes reduzidos são mesclas dos componentes originais, e o terceiro leva em conta se a ordenação dos componentes reduzidos obtidos é a mesma dos componentes originais, sendo este último critério o menos importante.

As medidas de similaridade $r_{1}(j)$, com $j=1,2, \ldots, 6$ para o critério de rejeição 0,70 , com $j=1,2, \ldots, 7$ para o critério de rejeição 0,60 e $Q_{1}$ baseados nos sexto e sétimo primeiros componentes, são dados na Tabela 6. 
Tabela 6 - Medidas de similaridade, $r_{1}(j)$ e $Q_{1}$, entre componentes para os conjuntos completo e reduzido dos descritores reprodutivos das espécies $P$.guenoarum e P.plicatulum com seis e sete descritores selecionados - 1996.

\begin{tabular}{ccc}
\hline \multirow{2}{*}{$\begin{array}{c}\text { Medidas } \\
\text { de }\end{array}$} & \multicolumn{2}{c}{ Critério de Rejeição } \\
\cline { 2 - 3 } Similaridade & \multicolumn{2}{c}{ Descritores Selecionados } \\
\cline { 2 - 3 } & CEF, LMS & PEF, DREF, EFL, CE, \\
\cline { 2 - 3 } & $0,631(1)^{+}$ & CEF, LMS, PR \\
\hline$r_{1}(1)$ & $0,721(2)$ & $0,663(1)$ \\
$r_{1}(2)$ & $0,549(4)$ & $0,818(2)$ \\
$r_{1}(3)$ & $0,482(5)$ & $0,710(3)$ \\
$r_{1}(4)$ & $0,681(3)$ & $0,518(5)$ \\
$r_{1}(5)$ & $0,628(4)$ & $0,775(4)$ \\
$r_{1}(6)$ & - & $0,605(5)$ \\
$r_{1}(7)$ & 0,626 & $0,772(7)$ \\
\hline$Q_{1}$ & 0,694
\end{tabular}

Entre parênteses: número do componente do conjunto de dados reduzido mais altamente correlacionado com o j-ésimo componente do conjunto de dados completo

$\mathrm{Na}$ avaliação da medida de similaridade entre componentes para o conjunto de dados completo e reduzido, $\mathrm{Q}_{1}$, os valores obtidos não apresentaram grande diferença entre os dois conjuntos de descritores selecionados.

A adição da variável PR (pilosidade do rácemo), provoca uma melhora nos valores dos coeficientes de correlação $r_{1}$ e uma ordenação igual dos componentes até o terceiro componente (os mais importantes). Observou-se que, para o conjunto de seis descritores selecionados, o quarto componente reduzido é uma mescla do terceiro e sexto componentes originais, e para o conjunto de sete descritores o quinto componente reduzido é uma mescla do quarto e sexto componentes originais. 
A variância associada aos quatro primeiros componentes dos dois conjuntos de dados reduzido, está em torno de $80 \%$ da variabilidade total. Conforme relatado anteriormente a inclusão da variável PR foi positiva para a seleção de descritores. Dessa forma, optou-se pelo conjunto de sete descritores como o mais bem sucedido na composição dos componentes originais. Portanto, os descritores selecionados foram: PEF, DREF, EFL, CE, CEF, LMS e PR.

\subsubsection{Seleção de Descritores Vegetativos}

No Apêndice - Tabela 4, encontram-se as médias e desvios padrão relativos aos 22 descritores vegetativos avaliados, em 26 acessos. Aqui o acesso de código BRA-009181, também não foi considerado nos cálculos por apresentar falhas na coleta dos dados.

Observando-se a Tabela 7, o primeiro componente concentrou $34,68 \%$ da variância total, o segundo $16,56 \%$, o terceiro $12,85 \%$ e o quarto $10,48 \%$, totalizando uma variância de $74,57 \%$. A variância acumulada pelos seis primeiros componentes foi de $88,18 \%$, os 16 últimos componentes concentrando apenas $11,82 \%$ da variância total .

A dispersão da variância em vários componentes tanto para os descritores reprodutivos (Tabela 2), quanto para os descritores vegetativos (Tabela 7) também foram obtidas por Pereira (1989) e Cury (1993) com mandioca, por Daher (1993) com capim elefante e Dias (1994) com cacau. Esta diluição da variação pode ser explicada pelo grande número e pela diversidade dos caracteres avaliados.

De acordo com a metodologia de Jolliffe (1972 e 1973), já citada anteriormente, descartaram-se 15 descritores (Tabela 7), que por ordem foram: LMBMEIO, LMLFBASE, DEPN, AMP, COPN, DIPEN, DEPEN, CHR, LMBAPICE, DEPLF, COPEN, DEPB, COPB, DIPLF e NMEN, um descarte que corresponde a $68 \%$ do conjunto de descritores considerados inicialmente. 
Como na seleção dos descritores reprodutivos, aqui também foram analisadas as estimativas das correlações entre os descritores dentro do grupo selecionado (Tabela 8), entre os descritores selecionados e descartados (Tabela 9) e entre os descritores dentro do grupo descartado (Tabela 10).

Pela Tabela 8 verificaram-se 7 combinações estatisticamente significativas, onde duas dessas combinações apresentaram magnitudes altas, as quais são: CMLF e CMB com $r=0,925$, LMLFMEIO e LMBBASE com $r=0,793$. Estes resultados são muito importantes mostrando a relação fisiológica entre a lâmina foliar e a bainha.

As Tabelas 9 e 10 apresentaram 24 e 19 combinações estatisticamente significativas, respectivamente, sendo que a magnitude da maioria dessas combinações pode ser considerada alta. Estes resultados estão de acordo com o obtido anteriormente para os descritores reprodutivos, mostrando que, neste caso, o método também eliminou os descritores não discriminantes.

Observou-se pela Tabela 9 que os descritores selecionados COPLF, CMLF, LMLFMEIO, CMB, LMBBASE E CMEN apresentaram o maior número de coeficientes de correlação significativos com os descritores descartados, indicando que estes explicam o mesmo fenômeno que aqueles descartados. Também pode-se notar que os descritores descartados DEPN e COPN não apresentaram correlação significativa com nenhum descritor selecionado. As estimativas das correlações (Apêndice - Tabela 5), mostraram que os descritores DEPN e COPN estão correlacionados entre si. Neste caso, pelo menos um deles deveria ter sido selecionado. 
Tabela 7 - Estimativas das variâncias (autovalor $\lambda_{\mathrm{j}}$ ), porcentagem acumulada das estimativas das variâncias (\%) dos 22 descritores vegetativos das espécies P.guenoarum e P.plicatulum avaliados em 26 acessos - 1996.

\begin{tabular}{|c|c|c|}
\hline Componentes & $\begin{array}{c}\text { Variâncias dos } \\
\text { Componentes }\left(\lambda_{j}\right)\end{array}$ & $\begin{array}{c}\text { Porcentagens Acumuladas } \\
(\%)\end{array}$ \\
\hline 1 & 7,6298 & 34,68 \\
\hline 2 & 3,6439 & 51,24 \\
\hline 3 & 2,8261 & 64,09 \\
\hline 4 & 2,3056 & 74,57 \\
\hline 5 & 1,8924 & 83,17 \\
\hline 6 & 1,1024 & 88,18 \\
\hline 7 & 0,6996 & 91,36 \\
\hline 8 & 0,5952 & 94,07 \\
\hline 9 & 0,3357 & 95,59 \\
\hline 10 & 0,2555 & 96,76 \\
\hline 11 & 0,2017 & 97,67 \\
\hline 12 & 0,1549 & 98,38 \\
\hline 13 & 0,1354 & 98,99 \\
\hline 14 & 0,0819 & 99,36 \\
\hline 15 & 0,0497 & 99,59 \\
\hline 16 & 0,0376 & 99,76 \\
\hline 17 & 0,0226 & 99,86 \\
\hline 18 & 0,0152 & 99,93 \\
\hline 19 & 0,0073 & 99,96 \\
\hline 20 & 0,0057 & 99,99 \\
\hline 21 & 0,0013 & 99,99 \\
\hline 22 & 0,0008 & 100,00 \\
\hline
\end{tabular}


Este fato não foi observado por Pereira (1989), porém o foi por Cury (1993), e Dias (1994). Cury (1993), considerou o número de caracteres descartados como exagerado. Desse modo este autor optou por adotar parcialmente a metodologia proposta por Jolliffe (1972 e 1973), propondo que o descarte das variáveis se procedesse através da técnica dos componentes principais, descartando-se a variável com maior coeficiente de ponderação do componente com menor autovalor em sucessivas análises, isto é, repetindo-se a análise a cada descarte considerando o novo conjunto de variáveis. A análise das correlações auxiliou o descarte pela eliminação das variáveis redundantes.

Para este caso, considerando-se também o critério de descartar as variáveis com o maior coeficiente do autovetor em componentes com autovalores inferiores a 0,60 , ao invés de 0,70 , como foi feito para as variáveis reprodutivas, o descritor a ser selecionado junto com os outros sete é o NMEN. Todos os comentários sobre as correlações entre os descritores selecionados e descartados, entre os descritores dentro do grupo selecionado e entre os descritores dentro do grupo descartado, continuam válidos para esta situação. 
Tabela 8 - Estimativas dos coeficientes de correlação entre os descritores dentro do grupo selecionado para os 22 descritores vegetativos das espécies P.guenoarum e P.plicatulum - 1996.

\begin{tabular}{|c|c|c|c|c|c|c|c|}
\hline \multirow{3}{*}{$\begin{array}{l}\text { Descritores } \\
\text { Selecionados }\end{array}$} & \multicolumn{7}{|c|}{ Descritores Selecionados } \\
\hline & COPLF & DIPB & CMLF & LMLF & CMB & LMB & CMEN \\
\hline & & & & MEIO & & BASE & \\
\hline COPLF & 1,000 & $-0,145$ & $-0,381$ & $-0,313$ & $-0,468$ & $-0,469^{*}$ & 0,021 \\
\hline DIPB & & 1,000 & $-0,058$ & $-0,243$ & $-0,064$ & $-0,079$ & $-0,036$ \\
\hline CMLF & & & 1,000 & 0,481 & $0,925^{* *}$ & $0,568 * *$ & $0,310^{*}$ \\
\hline LMLFMEIO & & & & 1,000 & 0,537 & $0,793 * *$ & 0,019 \\
\hline CMB & & & & & 1,000 & $0,508^{*}$ & $0,357^{*}$ \\
\hline LMBBASE & & & & & & 1,000 & 0,015 \\
\hline CMEN & & & & & & & 1,000 \\
\hline
\end{tabular}

${ }^{*},{ }^{* *}$ significativos ao nível de 0,05 e 0,01 de probabilidade, respectivamente, a significância foi obtida a partir do coeficiente de correlação de posto (Spearman). 
Tabela 9 -Estimativas dos coeficientes de correlação entre os descritores selecionados (horizontal) e descartados (vertical) para os 22 descritores vegetativos das espécies P.guenoarum e P.plicatulum - 1996

\begin{tabular}{llclllll}
\hline & \multicolumn{7}{c}{ Descritores Selecionados } \\
\cline { 2 - 8 } $\begin{array}{l}\text { Descritores } \\
\text { Descartados }\end{array}$ & COPLF & DIPB & CMLF & LMLF & CMB & LMB & CMEN \\
\hline AMP & $-0,210$ & $-0,036$ & 0,495 & 0,082 & $0,522^{*}$ & 0,215 & $0,836^{* *}$ \\
DIPLF & $0,690^{* *}$ & 0,042 & $-0,286$ & $-0,149$ & $-0,284$ & $-0,278$ & 0,245 \\
DEPLF & $0,585^{* *}$ & 0,199 & $-0,236$ & $-0,115$ & $-0,395$ & $-0,074$ & $-0,268$ \\
DEPB & 0,027 & $0,739^{* *}$ & 0,000 & $-0,047$ & $-0,008$ & $-0,004$ & $-0,133$ \\
COPB & 0,226 & $0,706^{* *}$ & $-0,085$ & $-0,236$ & $-0,115$ & $-0,209$ & $-0,088$ \\
DEPN & $-0,370$ & 0,047 & 0,329 & 0,013 & 0,334 & 0,071 & 0,141 \\
COPN & $-0,346$ & 0,122 & 0,272 & $-0,011$ & 0,267 & 0,053 & 0,096 \\
DIPEN & 0,269 & 0,327 & $-0,361^{*}$ & $-0,160$ & $-0,354$ & $-0,105$ & $-0,335$ \\
DEPEN & 0,278 & 0,347 & $-0,345^{*}$ & $-0,175$ & $-0,310$ & $-0,147$ & $-0,297$ \\
COPEN & 0,241 & 0,178 & $-0,378^{*}$ & $-0,143$ & $-0,395^{*}$ & $-0,094$ & $-0,435^{*}$ \\
LMLFBASE & $-0,351$ & $-0,235$ & 0,494 & $0,977^{* *}$ & 0,510 & $0,829^{* *}$ & $-0,028$ \\
LMBMEIO & $-0,451^{*}$ & $-0,098$ & $0,538^{*}$ & $0,883^{* *}$ & 0,523 & $0,966^{* *}$ & 0,075 \\
LMBAPICE & $-0,337$ & $-0,209$ & $0,586^{*}$ & $0,919^{* *}$ & 0,565 & $0,868^{* *}$ & 0,062 \\
NMEN & $-0,317$ & $-0,097$ & 0,441 & 0,055 & 0,456 & 0,248 & $0,429^{*}$ \\
CHR & $-0,287$ & $-0,102$ & $0,658^{* *}$ & 0,343 & $0,700^{* *}$ & 0,449 & $0,778^{* *}$ \\
\hline$*$
\end{tabular}

* , ** significativos ao nivel de 0,05 e 0,01 de probabilidade, respectivamente, a significância foi obtida a partir do coeficiente de correlação de posto (Spearman). 


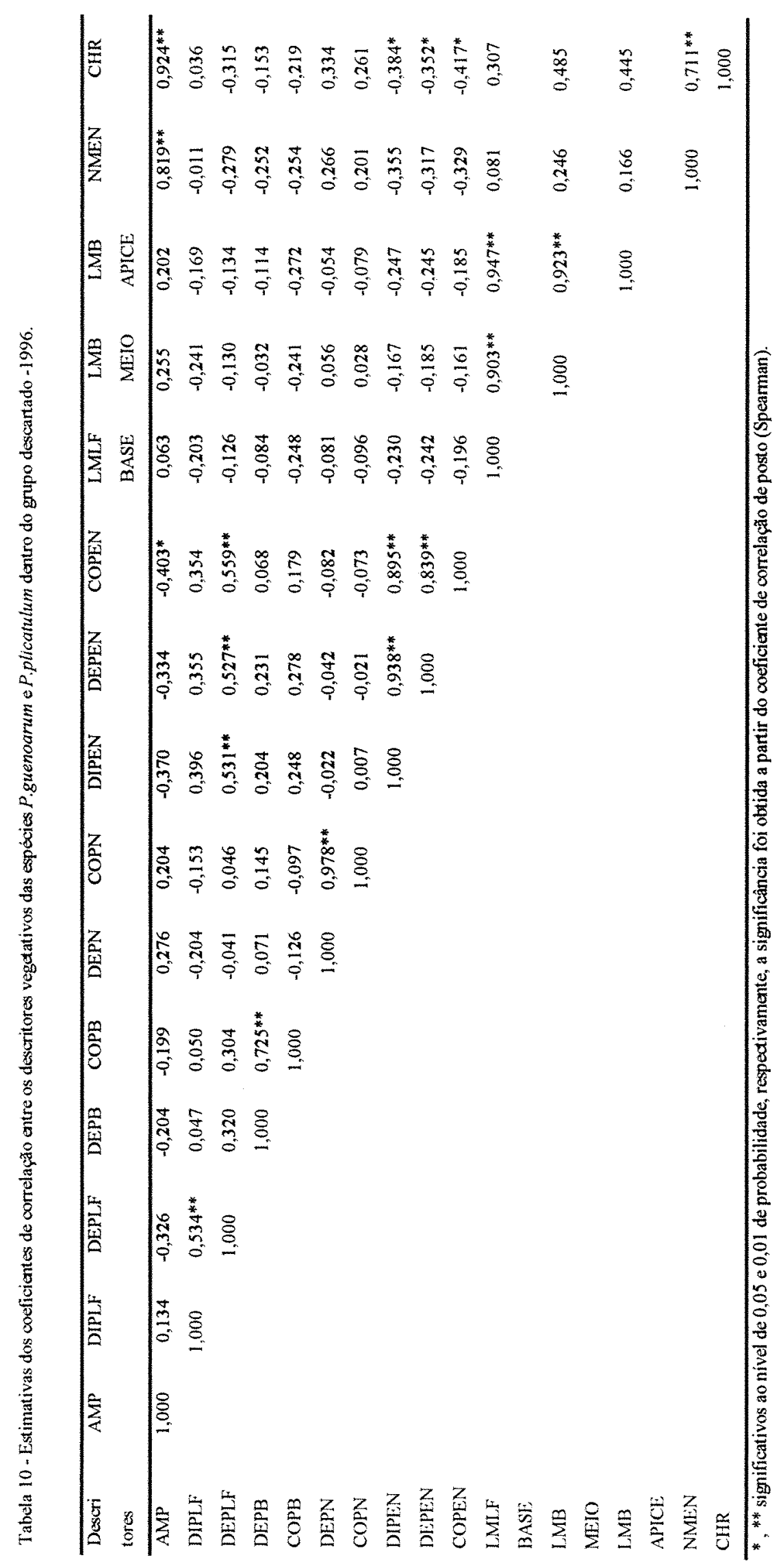




\title{
4.1.2.1. Comparação dos Componentes Principais de Descritores Vegetativos
}

\begin{abstract}
A Tabela 11 mostra as medidas de similaridade $r_{1}(j)$, com $j=1,2, \ldots, 7$ para o critério de rejeição 0,70 , com $j=1,2, \ldots, 8$ para o critério de rejeição 0,60 e $Q_{1}$, baseados nos sétimo e oitavo primeiros componentes.
\end{abstract}

Tabela 11 - Medidas de similaridade $r_{1}(j)$ e $Q_{1}$, entre componentes para os conjuntos completo e reduzido dos descritores vegetativos das espécies $P$.guenoarum e P.plicatulum com sete e oito descritores selecionados- 1996.

\begin{tabular}{|c|c|c|}
\hline \multirow{4}{*}{$\begin{array}{l}\text { Medidas } \\
\qquad \text { de } \\
\text { Similaridade }\end{array}$} & \multicolumn{2}{|c|}{ Critério de Rejeição } \\
\hline & 0,70 & 0,60 \\
\hline & \multicolumn{2}{|c|}{ Descritores Selecionados } \\
\hline & $\begin{array}{l}\text { CMEN,COPLF,DIPB,CMLF, } \\
\text { LMLFMEIO,CMB,LMBBASE }\end{array}$ & $\begin{array}{c}\text { NMEN,CMEN,COPLF,DIPB, } \\
\text { CMLF,LMLFMEIO,CMB, } \\
\text { LMBBASE }\end{array}$ \\
\hline$r_{1}(1)$ & $0,905(1)^{+}$ & $0,929(1)$ \\
\hline$r_{1}(2)$ & $0,753(2)$ & $0,872(2)$ \\
\hline$r_{1}(3)$ & $0,624(3)$ & $0,599(3)$ \\
\hline$r_{1}(4)$ & $0,510(3)$ & $0,534(3)$ \\
\hline$r_{1}(5)$ & $0,474(4)$ & $0,513(4)$ \\
\hline$r_{1}(6)$ & $0,400(3)$ & $0,406(3)$ \\
\hline$r_{1}(7)$ & $0,722(5)$ & $0,812(5)$ \\
\hline $\mathrm{r}_{1}(8)$ & - & $0,762(6)$ \\
\hline$\overline{Q_{1}}$ & 0,718 & 0,755 \\
\hline
\end{tabular}

Entre parênteses: número do componente do conjunto de dados reduzido mais altamente correlacionado com o j-ésimo componente do conjunto de dados completo. 
Analisando os valores dos coeficientes de correlação, $r_{1}$, e a medida de similaridade entre dois conjuntos, $Q_{1}$, para os critérios de rejeição 0,70 e 0,60 observouse não haver uma diferença muito grande entre eles, sendo que até mesmo a ordem dos componentes reduzidos e suas mesclas com os componentes completos foi a mesma. Verifica-se aqui que a adição da variável NMEN provocou uma melhora nos valores dos coeficientes de correlação $r_{1}$, porém não contribuiu para uma ordenação correta nem para evitar as mesclas dos componentes reduzidos.

A variável CMEN (comprimento médio de entrenós) é mais importante na discriminação dos acessos de Paspalum do que a variável NMEN (número médio de entrenós), uma vez que esta última não sofre tanta influência ambiental. Assim, tem-se os seguintes descritores como selecionados: COPLF, DIPB, CMLF, LMLFMEIO, CMB, LMBBASE e CMEN.

Para as variáveis vegetativas o critério adotado por Jolliffe (1972 e 1973), não se apresentou tão bem quanto para as variáveis reprodutivas. Deve-se ressaltar que as estimativas obtidas podem não ter refletido com boa exatidão as associações existentes entre os descritores tendo em vista o pequeno número de acessos (26) e a quantidade elevada de descritores (22) considerados.

\subsubsection{Análise de Variância Univariada dos Descritores Agronômicos}

As médias e desvios padrão relativos aos sete descritores agronômicos referente às avaliações anual, de inverno e de verão encontram-se no Apêndice - Tabelas 6, 7 e 8, respectivamente. Os acessos de códigos BRA-003824, BRA-003450 e as testemunhas não foram consideradas nos cálculos por apresentarem falhas na coleta dos dados.

A distribuição contínua dos descritores e o fato de os ensaios terem sido conduzidos com repetição, possibilitou realizar a análise de variância univariada para cada avaliação. 
Nas Tabelas 12, 13 e 14 encontram-se os resultados obtidos, ou seja: os quadrados médios de tratamentos, do resíduo, o teste $\mathrm{F}$ e o coeficiente de variação da análise de variância, para cada avaliação.

$O$ teste $F$ nos sete descritores de cada avaliação mostraram-se altamente significativos, o que evidencia haver diferenças genéticas entre os acessos para os sete descritores avaliados. O coeficiente de variação apresentou em geral valores médios, com exceção do descritor PRMSINV, o que evidencia uma boa estabilidade destes descritores contínuos. Segundo Pereira (1989), a estabilidade é um dos mais importantes atributos apresentados por um descritor, com vistas à caracterização de germoplasma.

Tabela 12 - Quadrados médios de tratamentos (QMT), do resíduo (QMR), valores do teste $\mathrm{F}$ e coeficientes de variação nas espécies P.guenoarum e P.plicatulum avaliação anual - 1996.

\begin{tabular}{lrrrr}
\hline Descritores & \multicolumn{1}{c}{ QMT } & QMR & F & CV (\%) \\
\hline PORMSANO & 1138,0001 & 211,9025 & $5,37^{* *}$ & 11,0 \\
PRMSANO & 73,0768 & 2,8683 & $25,48^{* *}$ & 17,1 \\
PPMSANO & 1,6433 & 0,3014 & $5,45^{* *}$ & 7,4 \\
FDNANO & 24,8207 & 2,1465 & $11,56^{* *}$ & 1,9 \\
DIVANO & 104,8040 & 15,6126 & $6,71^{* *}$ & 7,2 \\
NOTANO & 3,0335 & 0,0949 & $31,96^{* *}$ & 11,7 \\
REBROAN & 3,0332 & 0,1695 & $17,89^{* *}$ & 16,1 \\
\hline
\end{tabular}

** significativo ao nível de 0,01 de probabilidade pelo teste $\mathrm{F}$. 
Tabela 13 - Quadrados médios de tratamentos (QMT), do residuo (QMR), valores do teste $\mathrm{F}$ e coeficientes de variação nas espécies $P$.guenoarum e P.plicatulum avaliação de inverno - 1996.

\begin{tabular}{lrrrc}
\hline Descritores & \multicolumn{1}{c}{ QMT } & \multicolumn{1}{c}{ QMR } & \multicolumn{1}{c}{$\mathrm{F}$} & CV (\%) \\
\hline PORMSINV & 643,3537 & 108,7149 & $5,92^{* *}$ & 14,9 \\
PRMSINV & 10,6910 & 0,8434 & $12,68^{* *}$ & 26,0 \\
PPMSINVE & 4,5973 & 0,7603 & $6,05^{* *}$ & 10,2 \\
FDNINVER & 33,2695 & 3,7573 & $8,85^{* *}$ & 2,5 \\
DIVINVER & 183,5081 & 29,2260 & $6,28^{* *}$ & 9,7 \\
NOTAINV & 3,0848 & 0,2066 & $14,93^{* *}$ & 17,0 \\
REBROIN & 3,2525 & 0,1884 & $17,26^{* *}$ & 16,7 \\
\hline
\end{tabular}

** significativo ao nível de 0,01 de probabilidade pelo teste $\mathrm{F}$.

Tabela 14 - Quadrados médios de tratamentos (QMT), do resíduo (QMR), valores do teste $\mathrm{F}$ e coeficientes de variação nas espécies P.guenoarum e P.plicatulum avaliação de verão - 1996.

\begin{tabular}{lrrrc}
\hline Descritores & \multicolumn{1}{c}{ QMT } & \multicolumn{1}{c}{ QMR } & \multicolumn{1}{c}{ F } & CV (\%) \\
\hline PORMSVER & 372,469 & 115,1239 & $3,24^{* *}$ & 17,0 \\
PRMSVER & 27,4392 & 0,9685 & $28,33^{* *}$ & 16,5 \\
PPMSVER & 1,2751 & 0,1933 & $6,60^{* *}$ & 6,8 \\
FDNVERAO & 20,6321 & 8,1915 & $2,52^{* *}$ & 3,7 \\
DIVERAO & 71,6840 & 19,9454 & $3,59^{* *}$ & 8,4 \\
NOTAVER & 3,1388 & 0,0779 & $40,28^{* *}$ & 11,3 \\
REBROVER & 2,9554 & 0,1846 & $16,01^{* *}$ & 17,8 \\
\hline
\end{tabular}

*,** significativos ao nível de 0,05 e 0,01 de probabilidade pelo teste $\mathrm{F}$, respectivamente. 


\subsubsection{Seleção de Descritores Agronômicos}

As estimativas das variâncias de cada componente e a porcentagem acumulada destas estimativas, para os sete componentes principais obtidos a partir dos sete descritores agronômicos em cada avaliação, encontram-se nas Tabelas 15, 16 e 17.

As três tabelas mostraram que os quatro primeiros componentes explicaram pouco mais de $90 \%$ da variabilidade total, sendo que os dois primeiros componentes juntos concentraram mais de $70 \%$ dessa variabilidade.

Tabela 15 - Estimativas das variâncias (autovalor $\lambda_{\mathrm{j}}$ ), porcentagem acumulada das estimativas das variâncias (\%) dos 7 descritores agronômicos das espécies P.guenoarum e P.plicatulum avaliados em 27 acessos-avaliação anual 1996.

\begin{tabular}{ccc}
\hline Componentes & $\begin{array}{c}\text { Variâncias dos } \\
\text { Componentes }\left(\lambda_{\mathrm{j}}\right)\end{array}$ & $\begin{array}{c}\text { Porcentagens Acumuladas } \\
(\%)\end{array}$ \\
\hline 1 & 3,5652 & 50,93 \\
2 & 1,7833 & 76,41 \\
3 & 0,7266 & 86,79 \\
4 & 0,5593 & 94,78 \\
5 & 0,2863 & 98,87 \\
6 & 0,0677 & 99,83 \\
7 & 0,0117 & 100,00 \\
\hline
\end{tabular}


Tabela 16 - Estimativas das variâncias (autovalor $\lambda_{\mathrm{j}}$ ), porcentagem acumulada das estimativas das variâncias (\%) dos 7 descritores agronômicos das espécies P.guenoarum e P.plicatulum avaliados em 27 acessos- avaliação de inverno 1996.

\begin{tabular}{ccc}
\hline Componentes & $\begin{array}{c}\text { Variâncias dos } \\
\text { Componentes }\left(\lambda_{\mathrm{j}}\right)\end{array}$ & $\begin{array}{c}\text { Porcentagens Acumuladas } \\
(\%)\end{array}$ \\
\hline 1 & 3,1514 & 45,02 \\
2 & 2,4103 & 79,45 \\
3 & 0,7206 & 89,75 \\
4 & 0,4323 & 95,92 \\
5 & 0,1509 & 98,08 \\
6 & 0,0954 & 99,44 \\
7 & 0,0391 & 100,00 \\
\hline
\end{tabular}

Tabela 17 - Estimativas das variâncias (autovalor $\lambda_{\mathrm{j}}$ ), porcentagem acumulada das estimativas das variâncias (\%) dos 7 descritores agronômicos das espécies P.guenoarum e P.plicatulum avaliados em 25 acessos - avaliação de verão 1996.

\begin{tabular}{ccc}
\hline Componentes & $\begin{array}{c}\text { Variâncias dos } \\
\text { Componentes }\left(\lambda_{\mathrm{j}}\right)\end{array}$ & $\begin{array}{c}\text { Porcentagens Acumuladas } \\
(\%)\end{array}$ \\
\hline 1 & 3,2017 & 45,74 \\
2 & 1,8482 & 72,14 \\
3 & 0,9150 & 85,21 \\
4 & 0,6033 & 93,83 \\
5 & 0,3120 & 98,29 \\
6 & 0,0806 & 99,44 \\
7 & 0,0392 & 100,00 \\
\hline
\end{tabular}


Utilizando o critério de descarte adotado por Jolliffe (1972 e 1973), três descritores, para cada avaliação, seriam selecionados, conforme resultados das Tabelas 15, 16 e 17. Todavia o próprio Jolliffe (1973) e também Mardia et al.(1979) recomendam que se deva manter pelo menos quatro variáveis.

Assim, foram descartados três descritores em cada avaliação. Na avaliação anual e de inverno descartaram-se os mesmos descritores, que por ordem são: nota média de desenvolvimento vegetativo (NOTANO - NOTAINV), produção total de matéria seca $(\mathrm{kg} / \mathrm{ha}$ ) (PRMSANO - PRMSINV) e porcentagem média de digestibilidade "in vitro"(DIVANO - DIVINV). Na avaliação de verão descartaram-se: a nota média de desenvolvimento vegetativo (NOTAVER), a rebrota média (REBROVER) e a porcentagem média de proteína bruta na matéria seca (PPMSVER), conforme mostra a Tabela 18.

Tabela 18 - Descritores agronômicos das espécies P.guenoarum e P.plicatulum selecionados e descartados para as avaliações anual, de inverno e de verão 1996.

\begin{tabular}{lccccccc}
\hline & \multicolumn{7}{c}{ Descritores } \\
\cline { 2 - 8 } Avaliação & PORMS & PRMS & PPMS & FDN & DIV & NOTA & REBROTA \\
\hline ANUAL & $\mathrm{S}^{1}$ & $\mathrm{D}^{2}$ & $\mathrm{~S}$ & $\mathrm{~S}$ & $\mathrm{D}$ & $\mathrm{D}$ & $\mathrm{S}$ \\
INVERNO & $\mathrm{S}$ & $\mathrm{D}$ & $\mathrm{S}$ & $\mathrm{S}$ & $\mathrm{D}$ & $\mathrm{D}$ & $\mathrm{S}$ \\
VERÃO & $\mathrm{S}$ & $\mathrm{S}$ & $\mathrm{D}$ & $\mathrm{S}$ & $\mathrm{S}$ & $\mathrm{D}$ & $\mathrm{D}$ \\
\hline
\end{tabular}

\footnotetext{
${ }^{1}$ Descritor Selecionado

${ }^{2}$ Descritor Descartado
}

Pela Tabela 18 observou-se que os descritores PORMS (porcentagem média de matéria seca) e FDN (porcentagem média de fibra em detergente neutro), caracterizaram esse germoplasma em todas as avaliações. De modo contrário, o descritor 
NOTA (nota média de desenvolvimento vegetativo) não o caracterizou em nenhuma avaliação.

\subsubsection{Comparação dos Componentes Principais de Descritores Agronômicos}

Procedendo como no caso das variáveis reprodutivas, a Tabela 19 fornece as medidas de similaridade $r_{1}(j)$; com $j=1,2,3,4$ para o critério de rejeição $0,70 \mathrm{e}$ $\mathrm{Q}_{1}$.

Tabela 19 - Medidas de similaridade $r_{1}(j)$ e $Q_{1}$ entre componentes para o conjunto completo e reduzido dos descritores agronômicos das espécies $P$.guenoarum e P.plicatulum -1996.

\begin{tabular}{cccc}
\hline \multirow{2}{*}{$\begin{array}{c}\text { Medidas } \\
\text { de }\end{array}$} & \multicolumn{3}{c}{ Avaliação } \\
\cline { 2 - 4 } Similaridade & Dorual & Inverno & Verão \\
\cline { 2 - 4 } & PORM, PPMS, & PORMS, PPMS, & PORMS, PRMS, \\
& FDN, REBROTA & FDN, REBROTA & FDN, DIV \\
\hline$r_{1}(1)$ & $0,689(1)^{+}$ & $0,722(2)$ & $0,858(1)$ \\
$r_{1}(2)$ & $0,696(1)$ & $0,767(1)$ & $0,745(2)$ \\
$r_{1}(3)$ & $0,893(3)$ & $0,985(3)$ & $0,814(3)$ \\
$r_{1}(4)$ & $0,869(4)$ & $0,923(4)$ & $0,897(4)$ \\
\hline$Q_{1}$ & 0,730 & 0,779 & 0,826 \\
\hline
\end{tabular}

${ }^{+}$Entre parênteses: número do componente do conjunto de dados reduzido mais altamente correlacionado com o j-ésimo componente do conjunto de dados completo. 
Observando os coeficientes de correlação, $r_{1}$, verificou-se que os seus valores são altos para as três avaliações. O conjunto de variáveis selecionadas na avaliação de verão, teve para a medida de similaridade $Q_{1} \circ$ valor mais alto, e os componentes apresentaram-se corretamente ordenados.

Para a avaliação de inverno o primeiro e o segundo componentes estão em ordem trocada, porém o terceiro e quarto mantiveram-se na ordem correta. Com relação à avaliação anual o primeiro componente reduzido foi uma mescla dos componentes completos um e dois. Também dentre as três avaliações foi esta que apresentou o valor mais baixo para a medida de similaridade $\mathrm{Q}_{1}$.

Dessa forma, pode-se concluir que o conjunto de descritores selecionados para a avaliação de verão foi o mais bem sucedido na composição dos componentes originais.

\subsubsection{Seleção de Descritores Reprodutivos, Vegetativos e Agronômicos Analisados Conjuntamente}

Após a seleção de descritores reprodutivos, vegetativos e agronômicos separadamente, foi realizada uma análise de componentes principais considerando estes caracteres conjuntamente, a fim de se proceder a uma nova seleção. Desssa forma os caracteres analisados foram: PEF, PR, CE, CEF, DREF, EFL, LMS (reprodutivos), COPLF, DIPB, CMLF, LMLFMEIO, CMB, LMBBASE, CMEN (vegetativos), PORMSANO, PPMSANO, FDNANO, REBROAN, PRMSVER, DIVERAO (agronômicos). Observou-se na Tabela 20, que o primeiro componente concentrou $26,74 \%$ da variância total, o segundo $15,41 \%$, o terceiro $14,28 \%$ e o quarto $11,23 \%$, totalizando uma variância de $67,66 \%$. A variância acumulada pelos seis primeiros componentes foi de $81,61 \%$, os 14 últimos componentes concentrando apenas $18,39 \%$ da variância total. 
Aplicando a metodologia proposta por Jolliffe (1972 e 1973), descartaram-se 12 descritores (Tabela 20), que por ordem foram: REBROAN, CMLF, LMLFMEIO, CEF, PRMSVER, PPMSANO, DREF, PEF, COPLF, CMEN, LMS e FDNANO. Considerou-se necessário um novo descarte baseado na próxima variável de maior magnitude, para os casos em que a variável de maior coeficiente já tivesse sido descartada anteriormente em outro componente.

As Tabelas 21, 22 e 23 apresentam as estimativas das correlações entre os descritores dentro do grupo selecionado, entre os descritores selecionados e descartados e entre os descritores dentro do grupo descartado, respectivamente.

Pela Tabela 21 notou-se que há uma combinação de pares de variáveis, cujo coeficiente de correlação se mostrou estatisticamente significativo, mas de magnitude baixa. 
Tabela 20- Estimativas das variâncias (autovalor $\lambda_{\mathrm{j}}$ ), porcentagem acumulada das estimativas das variâncias (\%) dos 20 descritores botânico-agronômicos selecionados em 24 acessos das espécies P.guenoarum e P.plicatulum 1996.

\begin{tabular}{|c|c|c|}
\hline Componentes & $\begin{array}{c}\text { Variâncias dos } \\
\text { Componentes }\left(\lambda_{\mathrm{j}}\right)\end{array}$ & $\begin{array}{c}\text { Porcentagens Acumuladas } \\
(\%)\end{array}$ \\
\hline 1 & 5,3477 & 26,74 \\
\hline 2 & 3,0815 & 42,15 \\
\hline 3 & 2,8566 & 56,43 \\
\hline 4 & 2,2457 & 67,66 \\
\hline 5 & 1,7598 & 76,46 \\
\hline 6 & 1,0308 & 81,61 \\
\hline 7 & 0,8771 & 86,00 \\
\hline 8 & 0,7210 & 89,61 \\
\hline 9 & 0,5865 & 92,54 \\
\hline 10 & 0,4551 & 94,82 \\
\hline 11 & 0,3409 & 96,52 \\
\hline 12 & 0,2064 & 97,55 \\
\hline 13 & 0,1628 & 98,36 \\
\hline 14 & 0,1256 & 98,99 \\
\hline 15 & 0,1044 & 99,51 \\
\hline 16 & 0,0564 & 99,79 \\
\hline 17 & 0,0174 & 99,88 \\
\hline 18 & 0,0144 & 99,95 \\
\hline 19 & 0,0093 & 100,00 \\
\hline 20 & 0,0006 & 100,00 \\
\hline
\end{tabular}


Tabela 21- Estimativas dos coeficientes de correlação entre os descritores dentro do grupo selecionado das espécies P.guenoarum e P.plicatulum - 1996.

\begin{tabular}{|c|c|c|c|c|c|c|c|c|}
\hline \multirow{3}{*}{$\begin{array}{l}\text { Descritores } \\
\text { Selecionados }\end{array}$} & \multicolumn{8}{|c|}{ Descritores Selecionados } \\
\hline & $\overline{P R}$ & $\overline{C E}$ & EFL & DIPB & $\mathrm{CMB}$ & LMB & PORMS & DIVERAO \\
\hline & & & & & & BASE & ANO & \\
\hline$\overline{P R}$ & 1,000 & 0,090 & 0,282 & $-0,299$ & 0,039 & 0,039 & 0,022 & 0,011 \\
\hline $\mathrm{CE}$ & & 1,000 & 0,077 & $-0,303$ & $-0,061$ & $-0,221$ & 0,001 & 0,189 \\
\hline EFL & & & 1,000 & $-0,098$ & $-0,434$ & $-0,455$ & 0,035 & $-0,125$ \\
\hline DIPB & & & & 1,000 & 0,017 & $-0,005$ & 0,210 & $-0,187$ \\
\hline CMB & & & & & 1,000 & 0,426 & 0,128 & 0,342 \\
\hline LMB & & & & & & 1,000 & $-0,490^{*}$ & 0,121 \\
\hline \multicolumn{9}{|l|}{ BASE } \\
\hline PORMS & & & & & & & 1,000 & $-0,065$ \\
\hline \multicolumn{9}{|l|}{ ANO } \\
\hline DIVERAO & & & & & & & & 1,000 \\
\hline
\end{tabular}

* significativo ao nivel de 0,05 de probabilidade, a significância foi obtida a partir do coeficiente de correlação de posto (Spearman).

As Tabelas 22 e 23 apresentaram 20 e 12 combinações estatisticamente significativas, respectivamente. Para esta situação, os resultados obtidos também estão em concordância com os anteriores. Dessa forma, o método utilizado eliminou os descritores considerados como redundantes. 
Tabela 22- Estimativas dos coeficientes de correlação entre os descritores selecionados (horizontal) e descartados (vertical) em 24 acessos das espécies P.guenoarum e P.plicatulum - 1996.

\begin{tabular}{lcccccccc}
\hline & \multicolumn{7}{c}{ Descritores Selecionados } \\
\cline { 2 - 9 } Descritores & PR & CE & EFL & DIPB & CMB & LMB & PORMS & DIVERAO \\
Descartados & & & & & & BASE & ANO \\
\hline REBROAN & 0,014 & 0,178 & $-0,083$ & $-0,026$ & $0,690^{* *}$ & 0,071 & $-0,018$ & $0,426^{*}$ \\
CMLF & 0,070 & $-0,115$ & $-0,504$ & 0,002 & $0,907^{* *}$ & $0,511^{*}$ & 0,150 & 0,268 \\
LMLF & 0,073 & $-0,074$ & $-0,230$ & $-0,161$ & 0,321 & $0,836^{* *}$ & $-0,586^{*}$ & 0,323 \\
MEIO & & & & & & & & \\
CEF & 0,052 & $-0,386^{*}$ & $-0,400$ & 0,034 & $0,739^{*}$ & $0,737^{* *}$ & $-0,341$ & 0,264 \\
PRMS & 0,066 & 0,118 & 0,002 & 0,008 & $0,628^{*}$ & 0,022 & $-0,068$ & 0,346 \\
PPMS & $-0,070$ & 0,036 & 0,134 & 0,056 & $-0,009$ & 0,231 & $-0,492^{*}$ & 0,471 \\
DREF & $-0,418^{*}$ & $-0,148$ & $-0,285$ & 0,324 & 0,329 & 0,408 & $-0,210$ & 0,470 \\
PEF & 0,137 & $-0,065$ & 0,051 & $-0,070$ & $-0,178$ & $-0,076$ & $-0,441^{*}$ & 0,153 \\
COPLF & $-0,112$ & 0,355 & 0,185 & $-0,184$ & $-0,450$ & $-0,446^{*}$ & 0,018 & 0,340 \\
CMEN & 0,044 & $0,544^{* *}$ & $-0,302$ & $-0,078$ & $0,475^{* *}$ & 0,066 & $0,268^{*}$ & 0,186 \\
LMS & $-0,130$ & $0,352^{*}$ & $-0,318$ & $-0,412^{*}$ & $-0,096$ & 0,404 & $-0,241$ & 0,282 \\
FDNANO & $-0,238$ & $-0,629^{* *}$ & 0,033 & 0,156 & $-0,195$ & 0,004 & 0,248 & $-0,395$ \\
\hline
\end{tabular}

*,** significativos ao nivel de 0,05 e 0,01 de probabilidade, respectivamente, a significância foi obtida a partir do coeficiente de correlação de posto (Spearman). 







\subsubsection{Comparação dos Componentes Principais de Descritores Reprodutivos, Vegetativos e Agronômicos Analisados Conjuntamente}

A Tabela 24 fornece as medidas de similaridade $r_{1}(j)$; com $j=1,2, \ldots, 8$ para o critério de rejeição 0,70 , com $j=1,2, \ldots, 9$ para o critério de rejeição 0,60 e $Q_{1}$, baseados nos oitavo e nono componentes.

Tabela 24- Medidas de similaridade $r_{1}(j)$ e $Q_{1}$, entre os componentes para o conjunto completo e reduzido dos 20 descritores botânico-agronômicos das espécies P.guenoarum e P.plicatulum - 1996.

\begin{tabular}{ccc}
\hline & \multicolumn{3}{c}{ Critério de Rejeição } \\
\cline { 2 - 3 } Medidas & \multicolumn{3}{c}{0,70} & 0,60 \\
\cline { 2 - 3 } Similaridade & Descritores Selecionados \\
\cline { 2 - 3 } & LMBBASE, CE, EFL, DIPB, CMB, & PR, CE, EFL, DIPB, CMB, \\
& DIVERAO & DIVERAO, FDNANO \\
\hline$r_{1}(1)$ & $0,875(1)^{+}$ & $0,751(1)$ \\
$r_{1}(2)$ & $0,652(2)$ & $0,571(2)$ \\
$r_{1}(3)$ & $0,792(3)$ & $0,718(3)$ \\
$r_{1}(4)$ & $0,630(5)$ & $0,642(6)$ \\
$r_{1}(5)$ & $0,693(4)$ & $0,609(4)$ \\
$r_{1}(6)$ & $0,734(6)$ & $0,758(5)$ \\
$r_{1}(7)$ & $0,571(5)$ & $0,547(6)$ \\
$r_{1}(8)$ & $0,714(7)$ & $0,700(7)$ \\
$r_{1}(9)$ & - & $0,559(8)$ \\
$Q_{1}$ & 0,745 & 0,672 \\
\hline
\end{tabular}

Entre parênteses: número do componente do conjunto de dados reduzido mais altamente correlacionado com o j-ésimo componente do conjunto de dados completo. 
Verificou-se, pela Tabela 24, que os três primeiros componentes do conjunto reduzido estão corretamente ordenados para os dois critérios de rejeição. $\mathrm{O}$ quinto componente dos descritores selecionados pelo critério de rejeição 0,70 , foi uma mescla do quarto e sétimo componentes do conjunto completo. Quando se adotou o critério de rejeição 0,60 o sexto componente é que foi uma mescla desses mesmos componentes. Com a inclusão da variável FDNANO notou-se também uma diminuição na maioria dos valores dos coeficientes de correlação, $\mathrm{r}_{1}$, e na medida de similaridade $\mathrm{Q}_{1}$. Portanto, o conjunto de variáveis PR, CE, EFL, DIPB, CMB, LMBBASE, PORMSANO e DIVERAO, foi o mais bem sucedido na composição dos componentes originais.

Estes comentários mostraram a importância dos descritores reprodutivos e vegetativos, em relação aos agronômicos, uma vez que estes últimos são mais influenciados por fatores ambientais, não sendo útil, portanto, para a caracterização dos acessos.

Deve-se ressaltar que os resultados obtidos neste estudo aplicam-se às espécies P.guenoarum e P.plicatulum e, tendo sido obtidos de um conjunto específico de acessos, devem ser vistos como uma contribuição, para estudos futuros sobre forrageiras. 


\section{CONCLUSÕES}

Os resultados obtidos neste trabalho permitem as seguintes conclusões para as espécies P.guenoarum e P.plicatulum:

- Houve um descarte de $86 \%$ do total de descritores utilizados na caracterização dos acessos, evidenciando a necessidade de não se trabalhar com um número excessivo de descritores com este tipo de material.

- O método de descarte de variáveis através da utilização da análise de componentes principais, possibilitou uma redução de $53 \%, 68 \%$ e $43 \%$ dos descritores reprodutivos, vegetativos e agronômicos, respectivamente, do conjunto inicialmente considerado.

- Foram considerados como prioritários para compor relação de descritores os seguintes caracteres: PR, CE, EFL (reprodutivos), DIPB, CMB, LMBBASE (vegetativos) e PORMSANO, DIVERAO (agronômicos).

- Os descritores agronômicos por serem mais influenciados por fatores ambientais tiveram uma menor participação na caracterização dos acessos, uma vez que dos oito descritores selecionados, seis foram reprodutivos e vegetativos.

- O critério de descarte proposto por Jolliffe (1972 e 1973) se aplicou melhor para os descritores reprodutivos e agronômicos. 
- Com relação ao descarte de variáveis houve uma razoável concordância entre as avaliações anual e de inverno.

- Dentre os descritores agronômicos, a avaliação de inverno foi mais discriminativa que a de verão, uma vez que ela teve uma maior contribuição para a avaliação anual.

- O número de combinações de descritores reprodutivos selecionados e descartados que apresentaram correlação significativa entre si apresentou uma concordância com o esperado, confirmando que os descritores descartados eram redundantes, ou seja, que eles continham o mesmo tipo de informação dos descritores selecionados. Essa situação também se verificou com os descritores vegetativos apesar de a metodologia não ter sido satisfatória para essas variáveis. 


\section{REFERÊNCIAS BIBLIOGRÁFICAS}

AHAMAD, B. An analysis of crimes by the method of principal components. Applied Statistics. Ser.C, v.16, p. 17-35, Dec. 1967.

AKORODA, M.O. Principal component analysis and metroglyph of variation among nigerian yellow yams. Euphytica, v.32, n.2, p. 565-573, 1983.

ALCÂNTARA, P.B. ; BUFARAH, G. Plantas forrageiras gramíneas e leguminosas. 4.ed. São Paulo: Nobel, 1992. 162p.

BEALE, E.M.L. ; KENDALL, M.G. ; MANN, D.W. The discarding of variables in multivariate analysis. Biometrika, v.54, p. 357-366, 1967.

BEDIGIAN, D. ; SMYTH, C.A. ; HARLAN, J.R. Patterns of morphological variation in sesamum indicum. Economic Botany, v.40, n.3, p. 353-365, July/Sept. 1986.

CARADUS, J.R. ; MACKAY, A.C. ; WOODFIELD, D.R. ; BOSCH, J.VAN DEN ; WEWALA, S. Classification of a world collection white clover cultivars. Euphytica, v.42, n.1/2, p. 183-196, June 1989.

CASA, A.M. Caracterização do germoplasma de espécies do Paspalum (grupo Dilatata) pelo uso de marcadores bioquímicos e moleculares. Botucatu, 1995. 94p. Dissertação (Mestrado) - Instituto de Biociências, Universidade Estadual Paulista "Júlio de Mesquita Filho". 
COSTA, N.L., OLIVEIRA, J.R.C., GONÇALVEZ, C.A. Avaliação agronômica de gramíneas forrageiras em Rondonia, Brasil. Pasturas Tropicales, v.11, n.3, p. 21-24, 1989.

CRUZ, C.D. Aplicação de algumas técnicas multivariadas no melhoramento de plantas. Piracicaba, 1990. 188p. Tese (Doutorado) - Escola Superior de Agricultura "Luiz de Queiroz", Universidade de São Paulo.

CRUZ, C.D.; REGAZZI, A.D. Modelos biométricos aplicados ao melhoramento genético. Viçosa: Imprensa Universitária, 1994. 390p.

CURI, P.R. Agrupamento de países segundo agrupamento de padrão de vida. Revista Saúde Pública, v.27, n.2, p. 127-134, 1993.

CURY, R. Dinâmica evolutiva e caracterização de germoplasma de mandioca (Manihot esculenta, Crantz) na agricultura autóctone do sul do Estado de São Paulo. Piracicaba, 1993. 103p. Dissertação (Mestrado) - Escola Superior de Agricultura "Luiz de Queiroz", Universidade de São Paulo.

DAHER, R.F. Diversidade morfológica e isozimática em capim elefante (Pennisetum purpureum Schum.) Viçosa, 1993. 110p. Dissertação (M.S.) - Universidade Federal de Viçosa.

DIAS, L.A.S. Divergência genética e fenética multivariada na predição de híbridos e preservação de germoplasma cacau (Theobroma cacao L.). Piracicaba, 1994. 94p. Tese (Doutorado) - Escola Superior de Agricultura "Luiz de Queiroz", Universidade de São Paulo. 
FLURY, B ; RIEDWYL, H. Multivariate statistics a practical approach London: Chapman and Hall, 1988. 296p.

GOODMAN, M.M. ; PARTENIANI, E. The races of maize III choices of the appro priate characters for racial classification. Economic Botany, v.23, p. 265-273, July/Sept. 1969.

HUSSAINI, S.H. ; GOODMAN, M.M. ; TIMOTHY, D.H. Multivariate analysis and the geographical distribution of the world collection of finger millet. Crop Science, v.17 n.2, p. 257-263, Mar./Apr. 1977.

JEFFERS, J.N.R. Two case studies in the application of principal component analysis. Applied Statistics, v.16, p. 225-236, 1967.

JEFFERS, J.N.R. Principal component analysis of designed experiments. The Statistician, v.12, p. 230-242, 1972.

JOHNSON, R.A. ; WICHERN, D.W. Apllied multivariate statistical analysis. Englewood Cliffs: Prentice Hall, 1982. 593p.

JOLICOEUR, P. ; MOSIMANN, J.E. Size and shape variation in the painted turtle a principal component analysis. Growth, v.24, p. 339-354, 1960.

JOLLIFFE, I.T. Discarding variables in a principal component analysis. I: Artificial data. Applied Statistics, v.21, n.2, p. 160-173, 1972.

JOLLIFFE, I.T. Discarding variables in a principal component analysis. II:Real data. Applied Statistics, v.21, n.1, p. 21-31, 1973. 
MARDIA, K.V.; KENT, J.T.; BIBBY, J.M. Multivariate analysis. London: Academic Press, 1979. 520p.

MARTINEZ WILCHES, O. Evaluacion de 34 variedades de mani mediante tecnicas multivariadas. Revista ICA, v.18, p. 67-76, 1983.

MIRANDA, J.E.C. ; CRUZ, C.D. ; COSTA, C.P. Predição do comportamento de híbribridos de pimentão pela divergência genética dos progenitores. Revista Brasileira de Genética, v.11, n.4, p. 929-937, dez. 1988.

MORRISON, D.F. Multivariate statistical methods. 2.ed. Singapore: McGraw Hill, 1976. $415 p$.

PEREIRA, A.V. Utilização de análise multivariada na caracterização de germoplasma de mandioca (Manihot esculenta Crantz). Piracicaba, 1989. 180p. Tese (Doutorado) Escola Superior de Agricultura "Luiz de Queiroz", Universidade de São Paulo.

PULCINELLI, C.E. ; COUTO, H.T.Z. ; JESUS, R.M. ; GARCIA, A. Divergência genética entre populações de eucalipto. In: CONGRESSO NACIONAL DE GENÉTICA, Caxambu, 1993. Resumos. Ribeirão Preto: SBG., 1993. p. 355.

RISI, C.J. ; GALVEY, N.W. The pattern of genetic diversity in the andean grain crop quinoa. Euphytica, v.41. n.2, p. 135-145, Sept. 1989.

SAS INSTITUTE. SAS/STAT guide for personal computers: version 6. Cary, 1989. $1686 \mathrm{p}$. 
VALLS, J.F.M. Recursos genéticos de espécies de Paspalum no Brasil. In: ENCONTRO INTERNACIONAL SOBRE MELHORAMENTO GENÉTICO DE PASPALUM, Nova Odessa, 1987. Resumos. Nova Odessa: Instituto de Zootecnia, 1987. p. 1-3.

VAN LAAR, A. Multivariate analysis: a way to better understanding of complexity. South African Forestry Journal, v. 141, p. 34-41, June 1987.

WALKER, M.A. Some critical comments on "An analysis of crimes by the method of principal component analysis" by B.Ahamad. Applied Statistics. Ser.C, v.16, p. $36-39$, Dec. 1967. 
APÊNDICE 
Tabela 1 - Identificação dos Acessos da Coleção do gênero Paspalum, do CPPSE/EMBRAPA, São Carlos, S.P - 1996.

\begin{tabular}{|c|c|c|c|}
\hline $\begin{array}{c}\text { Número dos } \\
\text { Acessos }\end{array}$ & $\begin{array}{l}\text { Código da } \\
\text { Coleção }\end{array}$ & Espécie & Procedência \\
\hline 01 & BRA-003824 & P.guenoarum & Bela Vista - MG \\
\hline 02 & BRA-004898 & P.guenoarum & São Joaquim - SC \\
\hline 03 & BRA-006572 & P.guenoarum & São Borja - RS \\
\hline 04 & BRA-014851 & P.guenoarum & João Pinheiro - MG \\
\hline 05 & BRA-015083 & P.guenoarum & Rio Grande do Sul - RS \\
\hline 06 & BRA-003450 & P.plicatulum & Lages - SC \\
\hline 07 & BRA-004120 & P.plicatulum & Rio Pardo - RS \\
\hline 08 & BRA-008893 & P.plicatulum & São Gabriel - RS \\
\hline 09 & BRA-008940 & P.plicatulum & São Gabriel - RS \\
\hline 10 & BRA-009229 & P.plicatulum & Guaiba - RS \\
\hline 11 & BRA-011207 & P.plicatulum & Santa Maria - RS \\
\hline 12 & BRA-008869 & P.plicatulum & Minas do Botia - RS \\
\hline 13 & BRA- -008877 & P.plicatulum & Encruzilhada do Sul - RS \\
\hline 14 & BRA-008907 & P.plicatulum & São Gabriel - RS \\
\hline 15 & BRA-008982 & P.plicatulum & Lages - SC \\
\hline 16 & BRA-009032 & P.plicatulum & Itaqui - RS \\
\hline 17 & BRA-009211 & P.plicatulum & Guaiba - RS \\
\hline 18 & BRA-011274 & P.plicatulum & Soledade - RS \\
\hline 19 & BRA-012912 & P.plicatulum & Aral Moreira - MS \\
\hline 20 & BRA-014354 & P.plicatulum & Palmas - PR \\
\hline 21 & BRA-014389 & P.plicatulum & Palmas - PR \\
\hline 22 & BRA-006726 & P.plicatulum & Lagoa Vermelha - RS \\
\hline 23 & BRA-009181 & P.plicatulum & São Gabriel - RS \\
\hline 24 & BRA-012483 & P.plicatulum & Pereira Barretos - SP \\
\hline 25 & BRA-012939 & P.plicatulum & Aral Moreiral - MS \\
\hline 26 & BRA-013048 & P.plicatulum & Campo Largo - PR \\
\hline 27 & BRA-013111 & P.plicatulum & Balsa Nova - PR \\
\hline
\end{tabular}


Tabela 2 - Observações relativas aos descritores reprodutivos das espécies P.guenoarum e P.plicatulum avaliados em cada acesso, média geral e desvios padrão de cada descritor - 1996.

\begin{tabular}{|c|c|c|c|c|c|c|c|c|}
\hline \multicolumn{9}{|c|}{ Descritores } \\
\hline Acessos & $\mathrm{PE}$ & PEF & PR & PES & DREF & $\mathrm{EFL}$ & $\mathrm{EM}$ & $\mathrm{CE}$ \\
\hline 01 & 1,00 & 2,00 & 3,00 & 1,00 & 2,00 & 3,00 & 4,00 & 39,30 \\
\hline 02 & 1,00 & 2,00 & 3,00 & 1,00 & 2,00 & 11,00 & 12,00 & 25,70 \\
\hline 03 & 1,00 & 1,00 & 2,00 & 1,00 & 3,00 & 1,00 & 2,00 & 23,10 \\
\hline 04 & 2,00 & 4,00 & 3,00 & 2,00 & 3,00 & 12,00 & 12,00 & 17,90 \\
\hline 05 & 2,00 & 2,00 & 3,00 & 2,00 & 2,00 & 2,00 & 2,00 & 25,00 \\
\hline 06 & 1,00 & 2,00 & 1,00 & 1,00 & 2,00 & 11,00 & 12,00 & 34,60 \\
\hline 07 & 1,00 & 2,00 & 3,00 & 1,00 & 2,00 & 10,00 & 12,00 & 35,20 \\
\hline 08 & 1,00 & 2,00 & 3,00 & 1,00 & 2,00 & 10,00 & 11,00 & 34,10 \\
\hline 09 & 1,00 & 2,00 & 3,00 & 1,00 & 2,00 & 10,00 & 12,00 & 41,00 \\
\hline 10 & 1,00 & 2,00 & 3,00 & 1,00 & 2,00 & 11,00 & 12,00 & 32,50 \\
\hline 11 & 1,00 & 2,00 & 3,00 & 1,00 & 2,00 & 10,00 & 11,00 & 30,50 \\
\hline 12 & 2,00 & 4,00 & 1,00 & 1,00 & 2,00 & 4,00 & 5,00 & 21,50 \\
\hline 13 & 2,00 & 1,00 & 3,00 & 1,00 & 2,00 & 11,00 & 12,00 & 12,40 \\
\hline 14 & 1,00 & 4,00 & 3,00 & 1,00 & 3,00 & 1,00 & 3,00 & 24,00 \\
\hline 15 & 2,00 & 4,00 & 3,00 & 1,00 & 2,00 & 11,00 & 12,00 & 19,40 \\
\hline 16 & 2,00 & 4,00 & 3,00 & 1,00 & 2,00 & 10,00 & 11,00 & 23,90 \\
\hline 17 & 1,00 & 1,00 & 3,00 & 1,00 & 2,00 & 10,00 & 11,00 & 19,90 \\
\hline 18 & 2,00 & 4,00 & 3,00 & 1,00 & 2,00 & 8,00 & 9,00 & 15,40 \\
\hline 19 & 2,00 & 4,00 & 4,00 & 2,00 & 2,00 & 11,00 & 11,00 & 15,70 \\
\hline 20 & 2,00 & 4,00 & 3,00 & 1,00 & 2,00 & 10,00 & 11,00 & 14,20 \\
\hline 21 & 1,00 & 1,00 & 1,00 & 2,00 & 3,00 & 10,00 & 11,00 & 14,40 \\
\hline 22 & 2,00 & 2,00 & 3,00 & 2,00 & 2,00 & 12,00 & 1,00 & 24,30 \\
\hline 23 & 2,00 & 2,00 & 3,00 & 1,00 & 2,00 & 2,00 & 2,00 & 18,20 \\
\hline 24 & 1,00 & 1,00 & 3,00 & 1,00 & 2,00 & 9,00 & 11,00 & 17,70 \\
\hline 25 & 1,00 & 1,00 & 3,00 & 2,00 & 2,00 & 9,00 & 11,00 & 14,20 \\
\hline 26 & 1,00 & 1,00 & 3.00 & 1.00 & 2,00 & 4,00 & 5,00 & 15,70 \\
\hline Média & 1,42 & 2,35 & 2,77 & 1,23 & 2,15 & 8,19 & 8,77 & 23,45 \\
\hline $\begin{array}{l}\text { Desvio } \\
\text { Padrão }\end{array}$ & 0,50 & 1,20 & 0,71 & 0,43 & 0,37 & 3,72 & 4,05 & 8,39 \\
\hline
\end{tabular}


Tabela 2 - Observações relativas aos descritores reprodutivos das espécies P.guenoarum e P.plicatulum avaliados em cada acesso, média geral e desvios padrão de cada descritor - 1996. (Continuação)

\begin{tabular}{|c|c|c|c|c|c|c|c|}
\hline \multicolumn{8}{|c|}{ Descritores } \\
\hline Acessos & $\mathrm{CEF}$ & NMRI & NMPR & CMRML & CMS & LMS & NMS \\
\hline 01 & 19,90 & 12,00 & 79,70 & 15,80 & 3,63 & 2,17 & 111,50 \\
\hline 02 & 5,90 & 3,30 & 27,30 & 5,50 & 2,80 & 2,14 & 186,00 \\
\hline 03 & 48,70 & 13,00 & 55,80 & 15,90 & 3,42 & 2,03 & 349,00 \\
\hline 04 & 57,10 & 9,00 & 60,20 & 16,10 & 2,99 & 1,74 & 362,00 \\
\hline 05 & 36,00 & 5,70 & 68,00 & 11,80 & 3,18 & 2,18 & 296,00 \\
\hline 06 & 10,30 & 6,30 & 27,70 & 6,10 & 2,98 & 1,91 & 208,00 \\
\hline 07 & 10,90 & 4,70 & 42,30 & 6,70 & 3,03 & 1,78 & 230,00 \\
\hline 08 & 10,30 & 3,70 & 39,00 & 7,40 & 2,92 & 1,80 & 481,00 \\
\hline 09 & 8,20 & 3,00 & 35,70 & 7,00 & 3,11 & 2,16 & 379,50 \\
\hline 10 & 10,00 & 4,00 & 36,70 & 7,50 & 3,11 & 2,05 & 371,00 \\
\hline 11 & 6,70 & 6,70 & 28,00 & 6,20 & 3,21 & 1,97 & 438,50 \\
\hline 12 & 16,00 & 3,70 & 24,00 & 5,50 & 2,89 & 1,96 & 363,50 \\
\hline 13 & 20,70 & 4,30 & 39,90 & 7,00 & 2,90 & 1,91 & 369,50 \\
\hline 14 & 19,70 & 6,00 & 45,90 & 7,60 & 3,17 & 2,25 & 269,50 \\
\hline 15 & 17,60 & 3,70 & 37,80 & 7,50 & 2,91 & 1,73 & 401,50 \\
\hline 16 & 15,90 & 3,70 & 28,40 & 6,60 & 2,95 & 1,77 & 443,50 \\
\hline 17 & 16,80 & 3,30 & 27,70 & 6,30 & 2,86 & 1,85 & 416,00 \\
\hline 18 & 16,50 & 4,70 & 24,50 & 5,30 & 2,87 & 1,95 & 390,50 \\
\hline 19 & 32,30 & 7,30 & 38,90 & 9,30 & 2,91 & 1,53 & 578,50 \\
\hline 20 & 16,70 & 6,60 & 27,10 & 5,60 & 2,73 & 1,85 & 492,50 \\
\hline 21 & 14,60 & 4,70 & 27,30 & 4,70 & 2,66 & 1,85 & 546,50 \\
\hline 22 & 28,60 & 3,00 & 44,80 & 8,20 & 3,43 & 2,47 & 259,00 \\
\hline 23 & 50,40 & 5,00 & 59,40 & 17,10 & 3,97 & 2,07 & 311,50 \\
\hline 24 & 26,30 & 5,30 & 38,30 & 6,50 & 2,61 & 1,48 & 656,00 \\
\hline 25 & 17,70 & 3,70 & 40,10 & 7,40 & 2,73 & 1,78 & 543,00 \\
\hline 26 & 25,70 & 5,30 & 19,80 & 5,30 & 2,96 & 1,87 & 455,00 \\
\hline Média & 21,52 & 5,45 & 39,40 & 8,30 & 3,04 & 1,93 & 381,10 \\
\hline $\begin{array}{l}\text { Desvio } \\
\text { Padrão } \\
\end{array}$ & 13,58 & 2,54 & 14,78 & 3,73 & 0,31 & 0,22 & 128,03 \\
\hline
\end{tabular}




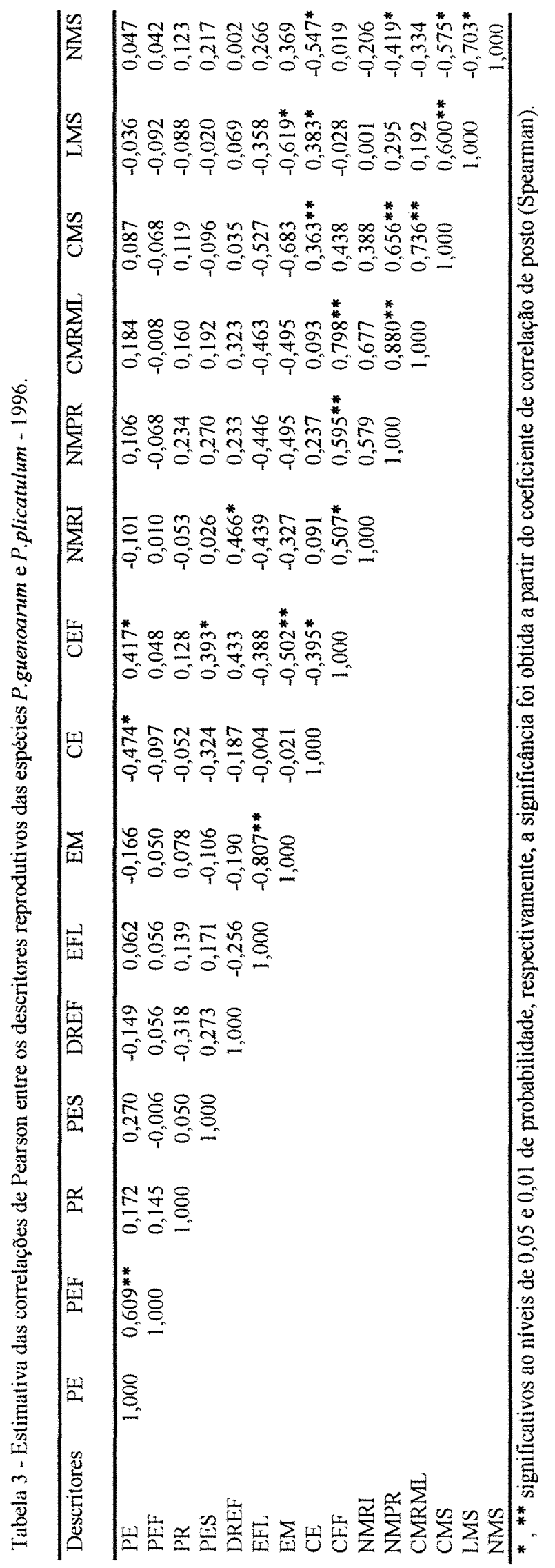


Tabela 4 - Observações relativas aos descritores vegetativos das espécies $P$.guenoarum e P.plicatulum avaliados em cads acesso, média geral e desvios padrão de cada descritor 1996.

\begin{tabular}{|c|c|c|c|c|c|c|c|c|c|c|c|}
\hline \multirow[b]{2}{*}{ Acessos } & \multicolumn{9}{|c|}{ Descritores } & \multirow[b]{2}{*}{ DIPEN } & \multirow[b]{2}{*}{ DEPEN } \\
\hline & $\mathrm{AMP}$ & DIPLF & DEPLF & COPLF & DIPB & DEPB & COPB & DEPN & COPN & & \\
\hline 01 & 24,00 & 3,00 & 2,00 & 2,00 & 1,00 & 1,00 & 1,00 & 1,00 & 1,00 & 1,00 & 1,00 \\
\hline 02 & 53,58 & 6,00 & 3,00 & 4,00 & 1,00 & 1,00 & 1,00 & 1,00 & 1,00 & 1,00 & 1,00 \\
\hline 03 & 100,80 & 5,00 & 2,00 & 2,00 & 5,00 & 2,00 & 2,00 & 1,00 & 1,00 & 1,00 & 1,00 \\
\hline 04 & 24,00 & 4,00 & 3,00 & 4,00 & 2,00 & 4,00 & 3,00 & 1,00 & 1,00 & 1,00 & 1,00 \\
\hline 05 & 32,40 & 2,00 & 4,00 & 3,00 & 1,00 & 1,00 & 1,00 & 1,00 & 1,00 & 1,00 & 1,00 \\
\hline 06 & 37,41 & 6,00 & 2,00 & 3,00 & 1,00 & 1,00 & 1,00 & 1,00 & 1,00 & 1,00 & 1,00 \\
\hline 07 & $\$ 2,17$ & 6,00 & 2,00 & 4,00 & 1,00 & 1,00 & 1,00 & 1,00 & 1,00 & 1,00 & 1,00 \\
\hline 08 & 47,20 & 5,00 & 2,00 & 3,00 & 5,00 & 2,00 & 3,00 & 1,00 & 1,00 & 1,00 & 1,00 \\
\hline 09 & 60,31 & 6,00 & 2,00 & 4,00 & 1,00 & 1,00 & 1,00 & 1,00 & 1,00 & 1,00 & 1,00 \\
\hline 10 & 49,50 & 6,00 & 2,00 & 4,00 & 1,00 & 1,00 & 1,00 & 1,00 & 1,00 & 1,00 & 1,00 \\
\hline 11 & 11,00 & 2,00 & 2,00 & 4,00 & 1,00 & 1,00 & 1,00 & 1,00 & 1,00 & 1,00 & 1,00 \\
\hline 12 & 25,50 & 5,00 & 4,00 & 4,00 & 5,00 & 3,00 & 3,00 & 1,00 & 1,00 & 2,00 & 3,00 \\
\hline 13 & 11,00 & 1,00 & 1,00 & 1,00 & $\$, 00$ & 4,00 & 2,00 & 1,00 & 1,00 & 1,00 & 1,00 \\
\hline 14 & 41,25 & 6,00 & 3,00 & 4,00 & 5,00 & 4,00 & 3,00 & 1,00 & 1,00 & 2,00 & 2,00 \\
\hline 15 & 22,00 & 2,00 & 2,00 & 4,00 & 2,00 & 2,00 & 4,00 & 1,00 & 1,00 & 1,00 & 1,00 \\
\hline 16 & 18,17 & 5,00 & 3,00 & 3,00 & 5,00 & 2,00 & 2,00 & 2,00 & 2,00 & 2,00 & 2,00 \\
\hline 17 & 11,96 & 5,00 & 4,00 & 3,00 & 4,00 & 2,00 & 3,00 & 1,00 & 1,00 & 2,00 & 2,00 \\
\hline 18 & 13,50 & 6,00 & 4,00 & 4,00 & 1,00 & 1,00 & 1,00 & 1,00 & 1,00 & 200 & 2,00 \\
\hline 19 & 35,52 & 4,00 & 4,00 & 2,00 & 5,00 & 4,00 & 2,00 & 3,00 & 3,00 & 1,00 & 1,00 \\
\hline 20 & 32,25 & 4,00 & 3,00 & 4,00 & 1,00 & 1,00 & 1,00 & 1,00 & 1,00 & 1,00 & 1,00 \\
\hline 21 & 33,84 & 2,00 & 2,00 & 3,00 & 5,00 & 2,00 & 3,00 & 1,00 & 1,00 & 1,00 & 1,00 \\
\hline 22 & 31,82 & 1,00 & 1,00 & 1,00 & 1,00 & 1,00 & 1,00 & 1,00 & 1,00 & 1,00 & 1,00 \\
\hline 23 & 80,37 & 1,00 & 1,00 & 1,00 & 1,00 & 1,00 & 1,00 & 4,00 & 3,00 & 1,00 & 1,00 \\
\hline 24 & 42,57 & 1,00 & 1,00 & 1,00 & 5,00 & 2,00 & 2,00 & 1,00 & 1,00 & 1,00 & 1,00 \\
\hline 25 & 39,59 & 5,00 & 4,00 & 4,00 & 5,00 & 4,00 & 4,00 & 1,00 & 1,00 & 1,00 & 1,00 \\
\hline 26 & 50,73 & 1,00 & 1,00 & 1,00 & 1,00 & 1,00 & 1,00 & 1,00 & 1,00 & 1,00 & 1,00 \\
\hline Média & 37.79 & 3,85 & 2,46 & 2,96 & 2,73 & 1,92 & 1,88 & 1,23 & 1,19 & 1,19 & 1,23 \\
\hline $\begin{array}{l}\text { Desvio } \\
\text { Padräo }\end{array}$ & 21,12 & 1,95 & 1,07 & 1,18 & 1,93 & 1,16 & 1,03 & 0,71 & 0,57 & 0,40 & 0,51 \\
\hline
\end{tabular}

Tabela 4-Observacões relativas aos descritores vegetativos das espécies $P$.guenoarum e $P$.plicatulum avaliados em cada acesso, média gerd e desvios padrão de cada descritor 1996 (Continuą̧ão)

\begin{tabular}{|c|c|c|c|c|c|c|c|c|c|c|c|}
\hline \multirow[b]{2}{*}{ Acessos } & \multicolumn{9}{|c|}{ Descritores } & \multirow[b]{2}{*}{ CMEN } & \multirow[b]{2}{*}{ CHR } \\
\hline & COPEN & CMLF & $\begin{array}{l}\text { LMLF } \\
\text { BASE }\end{array}$ & $\begin{array}{l}\text { LMIF } \\
\text { MEIO }\end{array}$ & $\mathrm{CMB}$ & $\begin{array}{l}\text { LMB } \\
\text { BASE }\end{array}$ & $\begin{array}{c}\text { LMB } \\
\text { MEIO }\end{array}$ & $\begin{array}{c}\text { LMB } \\
\text { APICE }\end{array}$ & NMEM & & \\
\hline 01 & 1,00 & 71,20 & 2,10 & 2,50 & 27,00 & 2,00 & 1,90 & 1,80 & 3,00 & 8,00 & 83,20 \\
\hline 02 & 1,00 & 23,90 & 0,50 & 0,70 & 10,70 & 0,80 & 0,80 & 0,60 & 4,70 & 11,40 & 85,18 \\
\hline 03 & 1,00 & 70,50 & 1,20 & 1,40 & 23,80 & 2,30 & 2,00 & 1,60 & 6,00 & 16,80 & 172,60 \\
\hline 04 & 1,00 & 53,30 & 1,00 & 1,40 & 21,80 & 1,60 & 1,30 & 1,10 & 3,00 & 8,00 & 99,00 \\
\hline 05 & 1,00 & 38,20 & 1,10 & 1,20 & 10,00 & 1,90 & 1,60 & 1,10 & 3,00 & 10,80 & 93,40 \\
\hline 06 & 1,00 & 27,60 & 0,70 & 0,80 & 11,40 & 1,40 & 1,20 & 0,70 & 4,30 & 8,70 & 82,31 \\
\hline 07 & 1,00 & 26,60 & 0,40 & 0,60 & 10,70 & 0,70 & 0,70 & 0,50 & 3,70 & 14,10 & 98,27 \\
\hline 08 & 1,00 & 34,60 & 0,40 & 0,40 & 13,70 & 0,80 & 0,70 & 0,60 & 4,00 & 11,80 & 91,60 \\
\hline 09 & 1,00 & 27,80 & 0,40 & 0,70 & 11,50 & 1,00 & 0,90 & 0,50 & 3,70 & 16,30 & 109,51 \\
\hline 10 & 1,00 & 31,70 & 0,40 & 0,60 & 11,00 & 0,80 & 0,70 & 0,70 & 3,00 & 16,50 & 92,00 \\
\hline 11 & 1,00 & 46,20 & 0,30 & 0,30 & 12,10 & 1,10 & 0,80 & 0,70 & 2,00 & 5,50 & 48,20 \\
\hline 12 & 3,00 & 24,30 & 0,30 & 0,50 & 10,80 & 0,90 & 0,80 & 0,50 & 3,00 & 8,50 & 63,00 \\
\hline 13 & 1,00 & 16,70 & 0,70 & 0,90 & 8,10 & 1,10 & 1,10 & 0,70 & 2,00 & 5,50 & 44,10 \\
\hline 14 & 2,00 & 35,30 & 0,70 & 1,00 & 12,80 & 1,60 & 1,30 & 0,70 & 3,30 & 12,50 & 84,95 \\
\hline 15 & 1,00 & 26,50 & 0,40 & 0,60 & 9,80 & 0,80 & 0,70 & 0,40 & 2,00 & 11,00 & 59,00 \\
\hline 16 & 2,00 & 26,30 & 0,20 & 0,40 & 9,80 & 0,90 & 0,70 & 0,30 & 2,30 & 7,90 & 57,97 \\
\hline 17 & 4,00 & 19,90 & 0,40 & 0,60 & 7,20 & 1,20 & 0,90 & 0,60 & 2,30 & 5,20 & 48,66 \\
\hline 18 & 4,00 & 22,30 & 0,60 & 0,80 & 5,20 & 1,30 & 1,00 & 0,70 & 3,00 & 4,50 & 45,40 \\
\hline 19 & 1,00 & 41,60 & 0,60 & 0,80 & 13,60 & 1,40 & 1,10 & 0,70 & 3,70 & 9,60 & 83,52 \\
\hline 20 & 1,00 & 26,70 & 0,50 & 0,60 & 9,30 & 1,20 & 1,00 & 0,60 & 4,30 & 7,50 & 63,15 \\
\hline 21 & 1,00 & 25,90 & 0,40 & 0,50 & 8,20 & 1,00 & 0,90 & 0,50 & 4,70 & 7,20 & 62,84 \\
\hline 22 & 1,00 & 29,40 & 1,40 & 1,60 & 11,00 & 2,20 & 1,80 & 1,40 & 3,70 & 8,60 & 84,72 \\
\hline 23 & 1,00 & 68,60 & 0,60 & 1,00 & 25,80 & 1,50 & 1,30 & 0,80 & 5,70 & 14,10 & 148,97 \\
\hline 24 & 1.00 & 45,60 & 0,40 & 0,50 & 19,10 & 1,30 & 1,00 & 0,50 & 3,30 & 12,90 & 86,57 \\
\hline 25 & 1.00 & 50,70 & 0,40 & 0,40 & 12,00 & 1,10 & 0,80 & 0,50 & 3,70 & 10,70 & 71,49 \\
\hline 26 & 1,00 & 53.50 & 0,40 & 0,40 & 19,60 & 1,20 & 0,80 & 0,50 & 5,70 & 8,90 & 92,13 \\
\hline Média & 1.38 & 37,11 & 0.63 & 0.82 & 13,31 & 1,27 & 1.07 & 0,74 & 3,58 & 10,10 & 8276 \\
\hline $\begin{array}{l}\text { Desvio } \\
\text { Padrão }\end{array}$ & 0,90 & 15,85 & 0,42 & 0,48 & 5,82 & 0,44 & 0,38 & 0,37 & 1,12 & 3,53 & 29,53 \\
\hline
\end{tabular}







Tabela 6 - Média das observações relativas aos descritores agronômicos das espécies P.guenoarum e P. plicatulum avaliados em cada acesso, média geral e desvio padrão de cada descritor - avaliação de anual - 1996.

\begin{tabular}{|c|c|c|c|c|c|c|c|}
\hline \multicolumn{8}{|c|}{ Descritores } \\
\hline Acessos & PORMS & PRMS & PPMS & FDN & DIV & NOTA & REBROTA \\
\hline 01 & 28,98 & 21,84 & 7,10 & 65,76 & 78,92 & 4,88 & 4,50 \\
\hline 02 & 39,61 & 5,59 & 8,48 & 76,57 & 60,07 & 2,25 & 2,00 \\
\hline 03 & 28,55 & 15,67 & 8,21 & 76,10 & 60,66 & 4,13 & 4,25 \\
\hline 04 & 25,69 & 19,49 & 9,38 & 72,87 & 73,81 & 4,38 & 4,50 \\
\hline 05 & 23,04 & 1,78 & 6,16 & 73,52 & 55,20 & 0,50 & 0,75 \\
\hline 06 & 34,17 & 10,77 & 7,07 & 80,32 & 62,07 & 3,38 & 3,50 \\
\hline 07 & 35,42 & 9,43 & 6,84 & 72,90 & 55,64 & 2,13 & 1,67 \\
\hline 08 & 35,31 & 10,13 & 6,87 & 73,16 & 58,81 & 3,00 & 2,83 \\
\hline 09 & 37,02 & 11,55 & 7,58 & 73,62 & 54,77 & 3,38 & 2,67 \\
\hline 10 & 33,66 & 13,51 & 7,26 & 75,94 & 57,13 & 3,50 & 3,50 \\
\hline 11 & 32,01 & 10,70 & 7,21 & 76,04 & 56,70 & 3,75 & 3,83 \\
\hline 12 & 32,69 & 6,06 & 7,64 & 78,42 & 54,21 & 2,00 & 1,75 \\
\hline 13 & 33,46 & 4,36 & 7,20 & 75,89 & 50,92 & 1,63 & 1,50 \\
\hline 14 & 33,66 & 5,10 & 8,72 & 76,68 & 64,75 & 1,88 & 2,00 \\
\hline 15 & 33,19 & 8,26 & 7,23 & 75,43 & 54,84 & 2,00 & 2,00 \\
\hline 16 & 31,45 & 17,15 & 8,03 & 73,76 & 56,28 & 3,50 & 3,38 \\
\hline 17 & 32,96 & 1,83 & 8,13 & 76,55 & 54,19 & 1,00 & 1,00 \\
\hline 18 & 23,43 & 2,06 & 7,98 & 79,70 & 53,19 & 1,00 & 0,88 \\
\hline 19 & 29,84 & 11,68 & 7,97 & 79,22 & 47,27 & 2,63 & 2,50 \\
\hline 20 & 29,67 & 10,55 & 7,54 & 84,71 & 54,67 & 2,63 & 2,50 \\
\hline 21 & 33,30 & 5,48 & 7,67 & 83,24 & 50,95 & 2,00 & 2,00 \\
\hline 22 & 24,75 & 0,42 & 8,18 & 77,97 & 37,86 & 0,50 & 1,00 \\
\hline 23 & 36,35 & 20,84 & 5,60 & 80,85 & 47,95 & 4,00 & 4,25 \\
\hline 24 & 35,87 & 17,47 & 7,88 & 73,96 & 53,28 & 4,75 & 4,88 \\
\hline 25 & 37,89 & 12,93 & 6,09 & 79,21 & 41,64 & 2,63 & 2,25 \\
\hline 26 & 52,13 & 4,50 & 5,89 & 82,82 & 44,19 & 1,75 & 1,50 \\
\hline 27 & 41,33 & 8,39 & 4,90 & 81,35 & 43,19 & 2,00 & 1,75 \\
\hline Média & 33,16 & 9,91 & 7,36 & 76,91 & 54,93 & 2,64 & 2,56 \\
\hline $\begin{array}{l}\text { Desvio } \\
\text { Padrão }\end{array}$ & 5,96 & 6,05 & 1,00 & 4,03 & 8,84 & 1,23 & 1,23 \\
\hline
\end{tabular}


Tabela 7 - Média das observações relativas aos descritores agronômicos das espécies $P$. guenoarum e $P$. plicatulum avaliados em cada acesso, média geral e desvio padrão de cada descritor - avaliação de inverno - 1996.

\begin{tabular}{|c|c|c|c|c|c|c|c|}
\hline \multicolumn{8}{|c|}{ Descritores } \\
\hline Acessos & PORMS & PRMS & PPMS & FDN & DIV & NOTA & REBROTA \\
\hline 01 & 29,69 & 6,66 & 8,91 & 64,06 & 78,92 & 5,00 & 5,00 \\
\hline 02 & 40,45 & 1,41 & 10,52 & 75,18 & 52,61 & 1,75 & 3,00 \\
\hline 03 & 31,13 & 4,84 & 9,67 & 73,90 & 65,27 & 3,75 & 4,50 \\
\hline 04 & 26,57 & 5,74 & 11,53 & 71,31 & 76,38 & 3,75 & 4,25 \\
\hline 05 & 11,78 & 0,71 & 5,94 & 72,96 & 55,87 & 0,50 & 0,50 \\
\hline 06 & 35,79 & 3,45 & 8,18 & 79,81 & 62,07 & 3,25 & 3,00 \\
\hline 07 & 35,31 & 2,89 & 8,27 & 69,30 & 61,32 & 1,75 & 2,00 \\
\hline 08 & 37,03 & 5,09 & 6,17 & 70,49 & 59,14 & 3,50 & 2,50 \\
\hline 09 & 36,58 & 3,73 & 9,64 & 72,15 & 60,52 & 3,75 & 3,50 \\
\hline 10 & 35,04 & 5,69 & 8,10 & 75,27 & 59,05 & 3,75 & 3,00 \\
\hline 11 & 32,59 & 4,46 & 7,89 & 76,17 & 59,80 & 4,00 & 3,50 \\
\hline 12 & 32,93 & 2,58 & 8,72 & 76,24 & 59,54 & 2,00 & 1,50 \\
\hline 13 & 34,77 & 1,36 & 8,02 & 74,74 & 55,66 & 2,00 & 1,75 \\
\hline 14 & 35,08 & 0,74 & 10,80 & 74,97 & 67,26 & 1,75 & 2,00 \\
\hline 15 & 32,19 & 3,46 & 7,33 & 73,27 & 59,39 & 2,00 & 2,00 \\
\hline 16 & 32,19 & 6,88 & 9,02 & 75,31 & 60,15 & 3,50 & 3,25 \\
\hline 17 & 30,98 & 0,42 & 10,42 & 75,00 & 58,17 & 1,00 & 1,00 \\
\hline 18 & 16,66 & 0,22 & 9,70 & 78,73 & 57,16 & 1,00 & 0,75 \\
\hline 19 & 30,15 & 4,06 & 9,73 & 78,29 & 52,13 & 3,00 & 2,75 \\
\hline 20 & 30,36 & 2,59 & 8,94 & 84,61 & 59,01 & 2,50 & 2,25 \\
\hline 21 & 34,92 & 0,87 & 8,78 & 82,32 & 51,83 & 1,75 & 1,75 \\
\hline 22 & 40,80 & 0,33 & 7,85 & 83,30 & 26,10 & 1,00 & 1,00 \\
\hline 23 & 42,59 & 7,92 & 6,63 & 82,11 & 42,75 & 4,50 & 4,50 \\
\hline 24 & 44,08 & 6,60 & 7,69 & 74,35 & 49,09 & 4,75 & 5,00 \\
\hline 25 & 46,01 & 5,92 & 5,77 & 81,72 & 35,32 & 2,75 & 2,50 \\
\hline 26 & 54,09 & 2,07 & 6,44 & 83,59 & 36,79 & 2,00 & 1,75 \\
\hline 27 & 52,84 & 4,80 & 4,17 & 81,62 & 37,44 & 2,00 & 1,75 \\
\hline Média & 34,91 & 3,54 & 8,33 & 76,32 & 55,51 & 2,68 & 2,60 \\
\hline $\begin{array}{l}\text { Desvio } \\
\text { Padrão }\end{array}$ & 8,97 & 2,31 & 1,72 & 4,94 & 11,81 & 1,24 & 1,28 \\
\hline
\end{tabular}


Tabela 8 - Média das observações relativas aos descritores agronômicos das espécies $P$.guenoarum e $P$. plicatulum avaliados em cada acesso, média geral e desvio padrão de cada descritor - avaliação de verão - 1996.

\begin{tabular}{crrrrrrr}
\hline & \multicolumn{7}{c}{ Descritores } \\
\cline { 2 - 7 } Acessos & PORMS & PRMS & PPMS & FDN & DIV & NOTA & REBROTA \\
\hline 01 & 38,77 & 4,18 & 6,43 & 77,97 & 67,54 & 2,75 & 1,50 \\
02 & 25,97 & 10,83 & 6,75 & 78,30 & 56,05 & 4,50 & 4,00 \\
03 & 24,82 & 13,74 & 7,24 & 74,44 & 71,23 & 5,00 & 4,75 \\
04 & 34,30 & 1,08 & 6,27 & 73,80 & 54,86 & 0,50 & 1,00 \\
05 & 35,54 & 6,54 & 5,42 & 76,50 & 49,97 & 2,50 & 1,50 \\
06 & 33,59 & 5,04 & 7,58 & 75,83 & 58,48 & 2,50 & 3,00 \\
07 & 37,46 & 7,82 & 5,53 & 75,08 & 49,02 & 3,00 & 2,25 \\
08 & 32,29 & 7,82 & 6,42 & 76,61 & 55,21 & 3,25 & 3,75 \\
09 & 31,43 & 6,24 & 6,54 & 75,91 & 53,61 & 3,50 & 4,00 \\
10 & 32,45 & 3,48 & 6,57 & 80,61 & 48,89 & 2,00 & 2,00 \\
11 & 32,14 & 3,00 & 6,38 & 77,05 & 46,19 & 1,25 & 1,25 \\
12 & 32,24 & 4,36 & 6,64 & 78,39 & 62,25 & 2,00 & 2,00 \\
13 & 34,20 & 4,80 & 7,13 & 77,60 & 50,30 & 2,00 & 2,00 \\
14 & 30,71 & 10,27 & 7,05 & 72,22 & 52,42 & 3,50 & 3,50 \\
15 & 34,93 & 1,41 & 5,83 & 78,10 & 50,22 & 1,00 & 1,00 \\
16 & 30,20 & 1,84 & 7,13 & 80,18 & 51,20 & 1,00 & 1,00 \\
17 & 29,53 & 7,62 & 6,21 & 80,15 & 42,43 & 2,25 & 2,25 \\
18 & 28,97 & 7,96 & 6,14 & 84,80 & 50,34 & 2,75 & 2,75 \\
19 & 31,69 & 4,61 & 6,56 & 84,17 & 50,08 & 2,25 & 2,25 \\
20 & 8,70 & 0,09 & 8,50 & 72,63 & 49,61 & 0,00 & 1,00 \\
21 & 30,11 & 12,92 & 4,58 & 79,59 & 53,15 & 3,50 & 4,00 \\
22 & 27,66 & 10,87 & 8,08 & 73,57 & 57,48 & 4,75 & 4,75 \\
23 & 29,77 & 7,01 & 6,42 & 76,69 & 47,96 & 2,50 & 2,00 \\
24 & 50,18 & 2,43 & 5,34 & 82,06 & 51,58 & 1,50 & 1,25 \\
25 & 29,82 & 3,59 & 5,63 & 81,09 & 48.95 & 2,00 & 1,75 \\
\hline Média & 31,50 & 5,98 & 6,49 & 77,73 & 53.16 & 2,47 & 2,42 \\
\hline Desvio & 6,83 & 3,70 & 0,87 & 3,32 & 6.41 & 1,25 & 1,22 \\
Padrão & & & & & & & \\
\hline & & & & & & &
\end{tabular}


Tabela 9 - Estimativa das correlações de Pearson entre os descritores agronômicos das espécies $P$.guenoarum e P.plicatulum - avaliação anual - 1996.

\begin{tabular}{llllllll}
\hline Descritores & PORMS & PRMS & PPMS & FDN & DIV & NOTA & REBROTA \\
\hline PORMS & 1,000 & 0,003 & $-0,481^{*}$ & 0.296 & $-0,309$ & 0,066 & $-0,025$ \\
PRMS & & 1,000 & $-0,015$ & $-0,365$ & $0,440^{*}$ & $0,940^{* *}$ & $0,919^{* *}$ \\
PPMS & & & 1,000 & $-0,242$ & $0,450^{*}$ & 0,096 & 0,138 \\
FDN & & & & 1,000 & $-0,634^{* *}$ & $-0,370$ & $-0,338$ \\
DIV & & & & & 1,000 & $0,524^{* *}$ & $0,510^{* *}$ \\
NOTA & & & & & & 1,000 & $0,979^{* *}$ \\
REBROTA & & & & & & 1,000 \\
\hline
\end{tabular}

*, ** significativos ao nível de 0,05 e 0,01 de probabilidade, respectivamente.

Tabela 10 - Estimativa das correlações de Pearson entre os descritores agronômicos das espécies P.guenoarum e P.plicatulum - avaliação de inverno - 1996.

\begin{tabular}{llllclcl}
\hline Descritores & PORMS & PRMS & PPMS & FDN & DIV & NOTA & REBROTA \\
\hline PORMS & 1,000 & 0,272 & $-0,428^{*}$ & $0,395^{*}$ & $-0,599^{* *}$ & 0,197 & 0,182 \\
PRMS & & 1,000 & $-0,232$ & $-0,220$ & 0,134 & $0,882^{* *}$ & $0,810^{* *}$ \\
PPMS & & & 1,000 & $-0,292$ & $0,599^{* *}$ & 0,027 & 0,185 \\
FDN & & & & 1,000 & $-0,736^{* *}$ & $-0,302$ & $-0,345$ \\
DIV & & & & & 1,000 & 0,324 & 0,357 \\
NOTA & & & & & & 1,000 & $0,938^{* *}$ \\
REBROTA & & & & & & & 1,000 \\
\hline
\end{tabular}

* ,** significativos ao nivel de 0,05 e 0,01 de probabilidade, respectivamente. 
Tabela 11 - Estimativa das correlações de Pearson entre os descritores agronômicos das espécies P.guenoarum e P.plicatulum - avaliação de verão - 1996.

\begin{tabular}{llllllll}
\hline Descritores & PORMS & PRMS & PPMS & FDN & DIV & NOTA & REBROTA \\
\hline PORMS & 1,000 & $-0,135$ & $-0,597^{* *}$ & 0,321 & 0,010 & $-0,030$ & $-0,218$ \\
PRMS & & 1,000 & $-0,076$ & $-0,151$ & 0,318 & $0,921^{* *}$ & $0,881^{* *}$ \\
PPMS & & & 1,000 & $-0,464^{*}$ & 0,268 & 0,032 & 0,174 \\
FDN & & & & 1,000 & $-0,281$ & $-0,150$ & $-0,222$ \\
DIV & & & & & 1,000 & $0,469^{*}$ & $0,417^{*}$ \\
NOTA & & & & & & 1,000 & $0,918^{* *}$ \\
REBROTA & & & & & & & 1,000 \\
\hline
\end{tabular}

$*,{ }^{* *}$ significativos ao nível de 0,05 e 0,01 de probabilidade, respectivamente. 


\section{Programa SAS para obtenção dos Componentes Principais e dos Coeficientes de}

\section{Correlações de Pearson e de Posto de Spearman}



De forma análoga, obtem-se os componentes principais e os coeficientes de correlações de Pearson e de posto de Spearman, para as variáveis vegetativas e agronômicas. 


\section{Programa SAS para obtenção da Análise de Variância para Dados Balanceados}

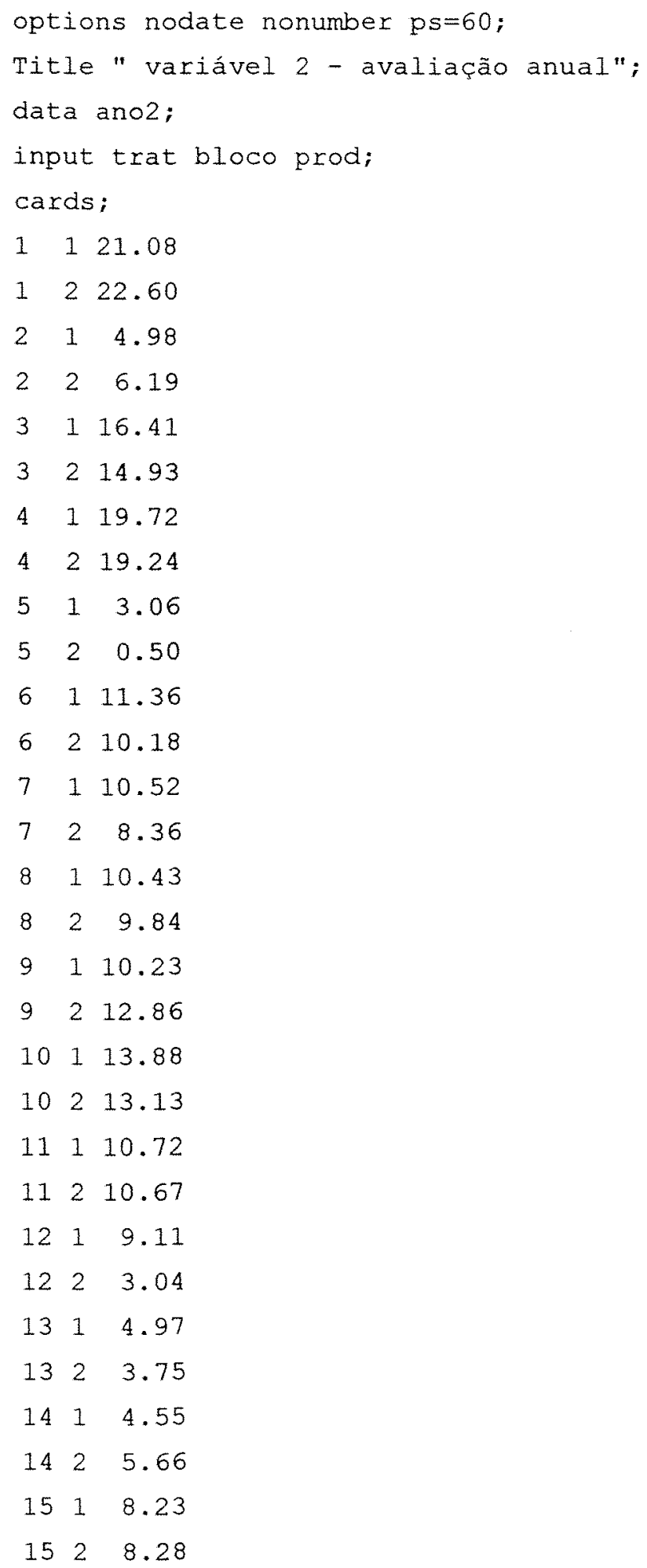


16116.46

$\begin{array}{lll}16 \quad 2 & 17.85\end{array}$

1711.94

$\begin{array}{lll}17 & 2 & 1.73\end{array}$

$\begin{array}{lll}18 & 1 & 2.44\end{array}$

$\begin{array}{lll}18 & 2 & 1.69\end{array}$

19110.52

19212.85

2018.20

$20 \quad 2 \quad 12.87$

2115.12

$212 \quad 5.84$

2210.005

$\begin{array}{lll}22 & 2 & 0.837\end{array}$

23118.67

23223.00

24116.84

24218.09

25110.36

$\begin{array}{lll}25 & 2 & 15.49\end{array}$

2615.82

$\begin{array}{lll}26 & 2 & 3.18\end{array}$

2718.54

$\begin{array}{lll}27 & 2 & 8.27\end{array}$

;

proc print;

proc anova data=ano2;

class trat bloco;

model prod=trat bloco;

run; 
Programa SAS para obtenção da Análise de Variância para Dados Desbalanceados




$\begin{array}{lll}25 & 2 & 6.49\end{array}$

$\begin{array}{lll}26 & 1 & 5.39\end{array}$

$\begin{array}{lll}26 & 2 & 7.77\end{array}$

$\begin{array}{lll}27 & 1 & 4.57\end{array}$

2725.76

;

proc print;

proc glm data=ano3;

class trat bloco;

model prod=trat bloco;

run; 